\title{
Overview of Radiation Environments and Human Exposures
}

\author{
John W. Wilson \\ NASA Langley Research Center \\ Hampton, VA 23681-0001
}

\begin{abstract}
Human exposures to ionizing radiation have been vastly altered by developing technology in the last century. This has been most obvious in the development of radiation generating devices and the utilization of nuclear energy. But even air travel has had its impact on human exposure. Human exposure increases with advancing aircraft technology as a result of the higher operating altitudes reducing the protective cover provided by the Earth's atmosphere from extraterrestrial radiations. This increase in operating altitudes is taken to a limit by human operations in space. Less obvious is the changing character of the radiations at higher altitudes. The associated health risks are less understood with increasing altitude due to the increasing complexity and new field components found in high altitude and space operations.
\end{abstract}

\section{Introduction}

The last half of the nineteenth century brought several scientific discoveries which would not only provide a foundation for much of the expanding technology of this century but would reveal the double sided nature so common to much of human technological advancement. First is the discovery of accelerated particles as cathode rays by Geissler and Pluecker in 1859 which are in such common use in our age and their extraction as an external beam by Lenard in 1893 (Wehr and Richards 1960). Lenard studied these extracted cathode rays using the less sensitive organic ketone scintillator as a detector to determine the cathode ray attenuation properties. Roentgen would repeat Lenard's experiments using a more sensitive barium scintillator (Harder 1995) in which the cathode ray attenuation experiments were confirmed but discovers more diffuse and penetrating "X-rays" produced at the florescent impact site of the cathode rays on the tube wall or an internal 
target. The potential medical use of these very penetrating X-rays was immediately recognized by Roentgen. However, within a year of the discovery of X-rays comes reports of adverse biological consequences as dermatitis, smarting of the eyes, and epilation (Upton 1989) followed by the first reported cancer within an X-ray produced ulcer (von Frieben 1903) and other adverse biological consequences (Upton 1989).

Next is the discovery by Becquerel in 1896 of radioactivity as rays emitted from some atoms (Wehr and Richards 1960, Halliday 1962). Becquerel was familiar with Roentgen's X-rays and went to great lengths to show that these new rays were the inherent properties of the uranium atom and not related to the fluorescence of the uranium salt crystal (Halliday 1962). E. Rutherford discovered two radioactivity rays (alpha and beta) of different penetrating power as emissions from uranium and Becquerel demonstrated that the physical properties of the beta rays are identical to cathode rays (Wehr and Richards 1960). The Curies discover that uranium ores contain other radioactive elements as radium and polonium. If the radioactive decay times of especially U-235, U-238, and Th-232 (and to a lesser extent Rb-87, and K-40) were not on the order of the age of the universe, there would be no significant natural radioactivity, the development of nuclear physics would have been delayed for decades, and nuclear energy based on fission would not have developed.

Lenard, Becquerel, the Curies, Rutherford, and Roentgen received four of the first Nobel prizes $(1901,1903,1905,1908)$ in physics and chemistry for these discoveries. The follow-on science from these discoveries has resulted in vast technologies on which we depend everyday. One common aspect of these developments is that the resulting rays all cause ions to be generated in air (and other matter) enhancing the conduction of electrical charge and producing chemical change.

It had long been known that ions were present in the atmosphere since charged condensers (electrometers) would slowly discharge over a period of time. Furthermore the discharge rate was increased by the known radioactivity rays, cathode rays, and X-rays. Over most of the land mass approximately 10 to 20 ion pairs per cubic centimeter are formed every second. Assuming the Earth's natural radioactivity as the source, repeat of the experiments over bodies of water in fact reduced the electrometer discharge rate (Hess and Eugster 1949). Estimates of attenuation of the most penetrating rays resulting from radioactivity in the atmosphere was 300 meters leading Th. Wulf, S.J. to compare discharge rates on the ground with those on top of the Eiffel Tower and he found 
the rate to be only half the ground level value and not a greatly reduced value as expected. Wulf rightly concluded that radiations must be penetrating from the top of the atmosphere, although that interpretation was controversial. Balloon flight data was obtained by various investigators but it was not until V. F. Hess developed an adequate electrometer experiment able to operate in the temperature and pressure extremes at balloon altitudes that conclusive evidence was found of radiations arriving at the top of the Earth's atmosphere. Hess's studies found the ionization rates to decrease with altitude up to 500 meters followed by a steady increase at higher altitudes to where the ground level rate is matched at 1500 meters. For this discovery, Hess would receive a Noble prize in physics (1936). Observations during a solar eclipse (incorrectly) brought the conclusion that the source was not the sun and probably came from deep space and the term "cosmic radiation" came into use in 1926 (Hess and Eugster 1949). Prior to this date the term "high altitude radiation" was in common use. J. Clay would discover that the ionization rates were smaller at lower latitudes in several voyages from Europe to the Dutch Indies in the period of 1927-1929 demonstrating that many of the rays are charged resulting in deflection in the geomagnetic field near the equator and allowing greater access in polar regions (Hess and Eugster 1949).

In the electrometer experiments, it was found that fresh air would result in faster discharge rates than older air (Hess and Eugster 1949). This is now understood to be due to short lived cosmogenic radioisotopes produced by the cosmic rays from atmospheric atoms and radon decay products. These are later recognized as important sources of human exposures.

That the cosmic rays consisted in part of charged particles was directly demonstrated by coincidence experiments using Geiger-Mueller tubes and resolving individual charged particle tracks within a Wilson cloud chamber. The later instrument lead to the discovery of the positron as part of the cosmic rays followed by the discovery of the charged mesons and further shed light on the important neutron component of the cosmic radiations in the atmosphere (Bethe et al. 1940). World wide surveys of cosmic ionization during the years 1931-1932 were made by several groups and Hess of Austria studied time variations associated with solar activity cycle on a mountain top from 1931-1937. Global radiation levels correlated well with the expected effects of the geomagnetic deflection of cosmic radiations. A world wide network of stations began to develop leading to observed short term fluctuations in the global ionization rates simultaneously in both the southern and northern hemispheres and correlated with solar disturbances (Hess and Eugster 1949). Observed 
large increases in the ionization rates would be attributed to particles coming directly from the solar events (figure 1) while more modest decreases over a few days as seen for the July-August 1946 event were attributed to disturbance of the local interplanetary medium by which approaching cosmic rays were excluded from the local Earth environment (Forbush decrease). It was now clear that extraterrestrial radiations from both the sun and the galaxy were contributing to the atmospheric ionization levels. The last piece of important evidence from a human exposure perspective was the discovery of heavy ion tracks by Phyllis Frier and coworkers (1948) using nuclear emulsion track detectors in high altitude balloon flight. Although the initial emphasis of this discovery was the ability to sample cosmic matter, attention would turn to the possibility of human exposure by these ions in high altitude aircraft and future space travel (Armstrong et al. 1949, Schaefer 1950).

E. Goldstein introduced the term "cathode rays" at the time (1876) of his discovery of the canal rays (positive ion beams, Hess and Eugster 1949). He suggested, incorrectly, that "cathode rays" from the sun were responsible for the observed aurora. C. Stoermer (1955) studied the equations of charged particle motion in the geomagnetic field to understand the auroral patterns and found a general equation for the
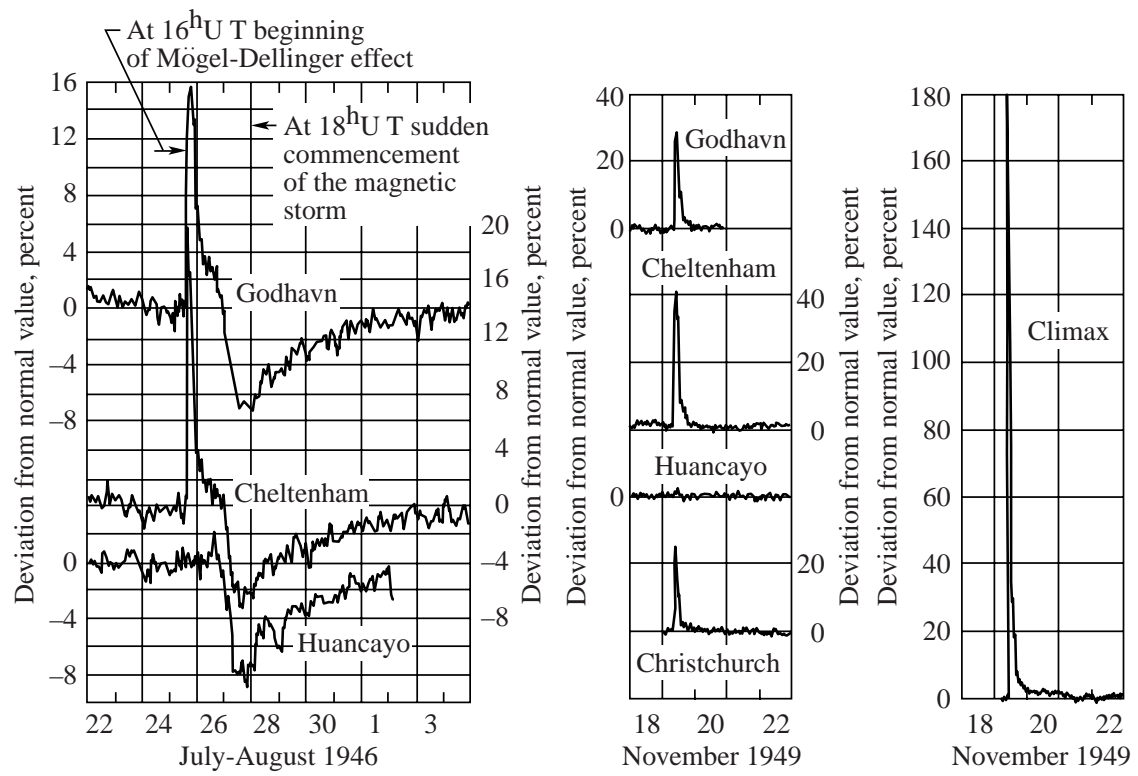

Figure 1. Ground level ion chamber observations of solar particle events of 1946 and 1949. (From Foelsche et al. 1974) 
solutions which were open to asymptotic motion. He also found solutions which were bound with no asymptotic solution which he recognized as not contributing to aurora but failed to suggest that these regions may be filled with trapped particles which are in fact the source of the aurora during conditions of extreme geomagnetic disturbance. The trapped radiations were directly observed by the first US satellite with a GeigerMueller tube (Van Allen et al. 1958) and are largely confined to the "forbidden" regions of Stoermer's theory on the motion of charged particles in a magnetic dipole field (left hand proton contours in figure 2). The inner zone particles shown on the left of figure 2 consist of stable trapped radiations while the so-called outer zone particles on the right of figure 2 consist of a transient zone where particles of the solar wind are inserted into the magnetosphere through the geomagnetic tail and radially diffuse inward until they are depleted by precipitation into the Earth's atmosphere near the poles. It is these outer zone particles that mainly form the aurorae during geomagnetic disturbances. With the discovery of the magnetically trapped radiations, no new sources of natural radiations have been found (except of course those of the same classes in other planetary bodies). Even so, human activity has enhanced human exposures to natural radiations due to technological development. Manmade radiation sources would also continue to increase in intensity and the number of people exposed. In what follows we will summarize the more traditional manmade sources and enhancements as radiation generating machines and nuclear energy related sources. Special attention will be given to the quality of the radiations involved as this also relates to the interpretation of the associated risks. Of particular interest will be the comparison of the level

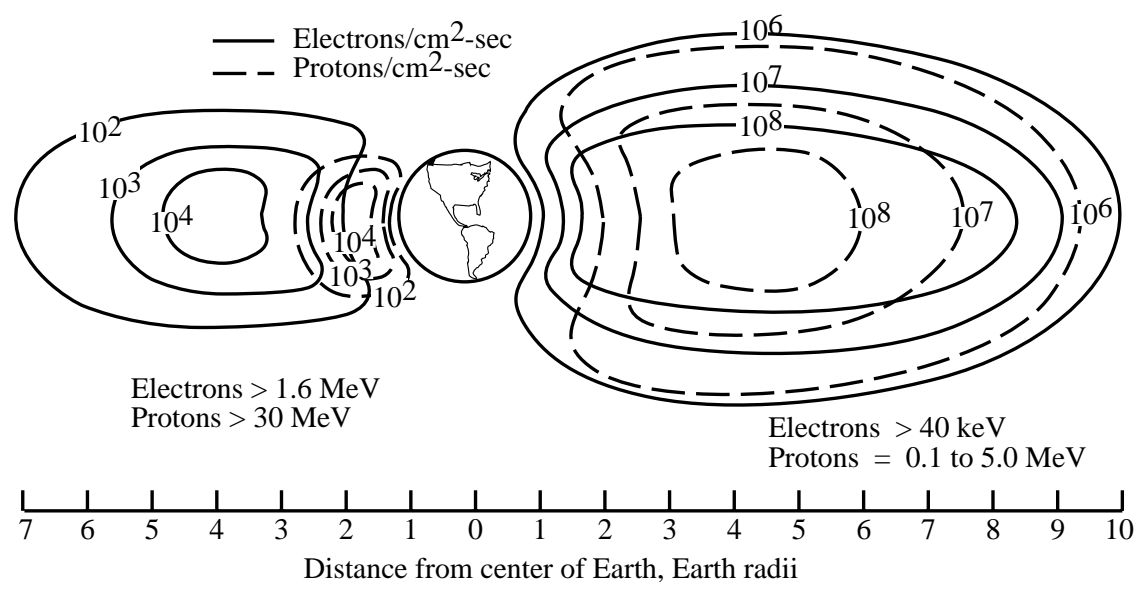

Figure 2. Near-Earth trapped radiation (Parker and West 1973). 
of exposures and the radiation quality of various groups of occupationally exposed individuals. We will give greatest attention to detail for space and aircraft radiation sources which are the primary topics of the present meeting.

\section{Basic Concepts and Terminology}

The concept of field refers to the spatial distribution of a physical quantity which may vary with time of observation. lonizing radiation refers to the field associated with a physical agent which has the property of producing ions within a material substance placed within the field. The ionizing radiation field itself consists of particles streaming from some source and could be either charged or neutral particles. The ionization within substances is ultimately associated with the transfer of kinetic energy of the field particles to bound electrons of the substance by which molecular changes are initiated. In the case of charged particle fields (electrons, muons, pions, protons, alpha particles, and other ions), the ionization is caused directly through coulombic interaction between the radiation field constituents and bound electrons in the substance. In the case of neutral particle fields (photons and neutrons), the ionization is mainly indirect by the release of an energetic charged particle within the substance. Ionization induced by photons is mainly the result of transfer of photon energy to a bound electron providing sufficient kinetic energy to the electron resulting in additional ionizing events. Ionization induced by neutrons is through a nuclear collision event in which a recoiling nucleus or energetic charged nuclear reaction products are the agents of ionization.

The ionization process in living tissues consists of ejecting bound electrons from the cellular molecules leaving behind chemically active molecular species (radicals) which are the source of adverse changes. Cellular processes are able to overcome most of this injury as many of the radicals resulting from radiation injury are similar to those produced in ordinary metabolic processes for which the cell has developed recovery mechanisms needed for long term survival (Billen 1990). Conventional wisdom considers changes in the DNA structure as the substantive target of radiation injury which may also be injured directly by the passing ionizing particle. The ability of the cell to repair the effects of ionization depends in part on the number of such events occurring within the cell from the passage of a single particle and the rate at which such passages occur. The number of ionization events per particle passage is related to the physical processes by which particle kinetic energy is transferred to the cellular bound electrons. 
Charged particles have a long range interaction and tend to loose energy through small discrete events over short mean free paths on the order of atomic dimensions and appears as a continuous slowing down process similar to motion of an object through a viscous media. The rate of energy loss increases rapidly with increasing charge of the particle and decreasing speed. The rate of energy loss of electrons and singly charged ions at high energies are more like photon exposures in their biological consequences. The distance traveled depends on the inertia and massive particles are more penetrating than lighter particles of the same charge and speed. Uncharged particles have longer free paths and for neutrons larger energy transfers per event resulting in energy losses which appear as isolated occurrences along the particle's path. The electrons resulting from photon interactions produce few ions in isolated cells and the rate at which such events occur in a given cell is important since repair of a single event is relatively efficient unless many events occur within the repair period (Wilson et al. 1993). Indeed, the single photon event may do little more than add a few free radicals to the melee of metabolic related radicals and have little or no added consequence (Billen 1990). The effects on health risks of dose rate of the exposures is included in protection through a dose rate effectiveness factor DREF. The massive low energy ions resulting from neutron interactions always produce copious ions in the struck cell and repair is less efficient for such events. Unlike photon doses which are ineffective in causing injury unless many interactions occur within the cell's repair period (i.e., high dose rates), neutron exposures under most conditions will be singular events in a few cells and will not be so dependent on the dose rate as is true for high LET radiation events of heavy ions (Schaefer 1952, Curtis et al. 1995, Wilson et al. 1995a). Such effects in radiation protection practice are accounted for through an LET dependent quality factor as discussed below.

Most of human experience with radiation exposures is from the nuclear detonations of W. W. II consisting mainly of gamma ray like radiations produced in a few milliseconds within the blast. The fatal cancer risks for the W. W. II survivors is approximately related to the gamma ray dose as

$$
\mathrm{R} \approx \mathrm{k}_{\gamma} \mathrm{D}_{\gamma}
$$

where $\mathrm{k}_{\gamma}$ is the high dose rate risk coefficient and $\mathrm{D}_{\gamma}$ is the gamma energy absorbed per unit mass of tissue. The risk from a gamma ray dose accumulated slowly over a lifetime is assumed to be given by

$$
\mathrm{R} \approx \mathrm{k}_{\gamma} \mathrm{D}_{\gamma} / \mathrm{DREF}
$$


where DREF is the dose rate effectiveness factor (usually taken as 2 or 2.5) and $D_{\gamma}$ is now the lifetime accumulated dose. So-called high LET radiations are more effective in adding to risk than low LET gamma rays. This effect is summarized in the relative biological effectiveness (RBE) which is the ratio of gamma dose $D_{\gamma}$ to high LET dose $D$ which results in the same risk. Based on observations of RBE, a quality factor is defined (ICRP 1991) for use in risk estimates in protection practice as

$$
\mathrm{R} \approx \mathrm{k}_{\gamma} \mathrm{Q} \mathrm{D} / \mathrm{DREF}
$$

The quantity $H=Q D$ is termed the dose equivalent and the low dose rate risk coefficient $k=k_{\gamma} / D R E F$. The associated risk is approximately given as

$$
\mathrm{R}=\mathrm{kH}
$$

The quality factor $Q$ describes the inability of the exposed cells to repair the radiation induced injury as related to the number of chemical precursors produced within or near the cell nucleus. The relative risk of producing fatal cancer for average number of ionizations within the cell nucleus is shown in figure 3 . The figure indicates that the cell can

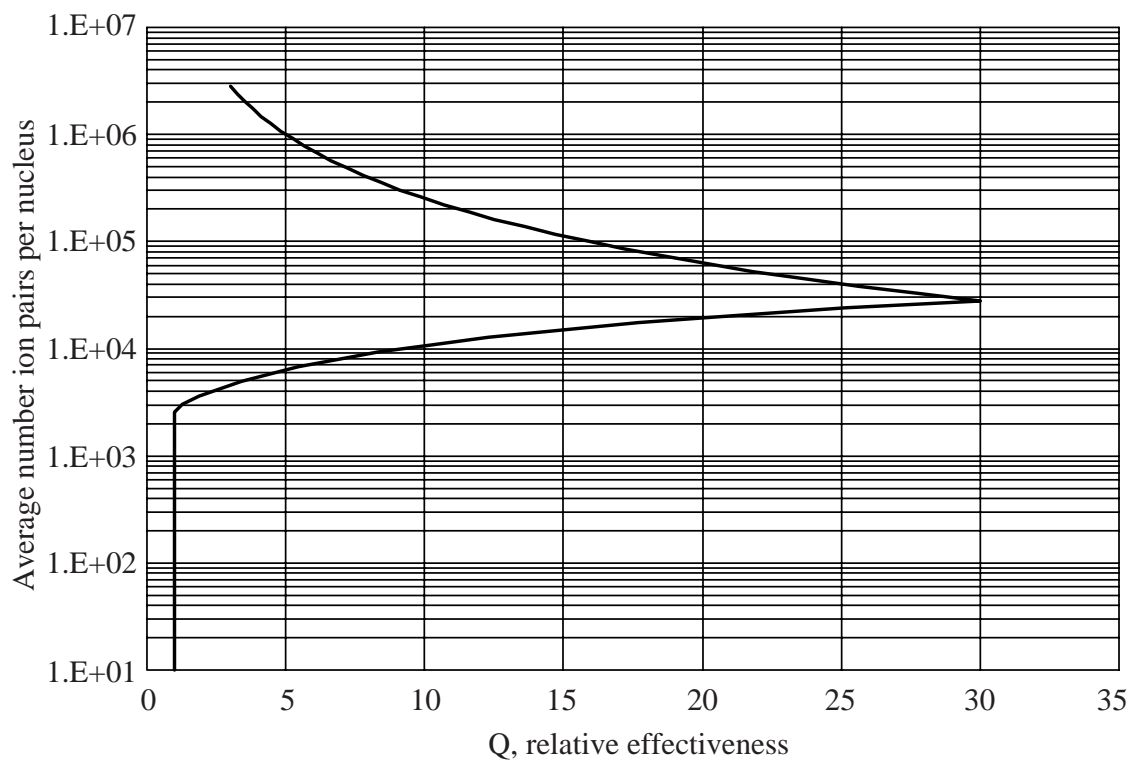

Figure 3. Average number of ion pairs formed in cell nucleus as related to relative effectiveness to cause cancer. 
handle up to a few thousand ion pairs without increased risk but 25,000 ion pairs has a greatly enhanced ability of causing cancer. The decline at very high numbers of ion pairs would indicate that the cell is likely not to survive and therefore not contribute to carcinogenesis. Note that $\mathrm{H}$ through the use of $Q$ places all radiations on an equal scale and at low dose and dose rate the associated risks are additive. Although $Q$ for cancer risks are routinely used to estimate the prenatal exposure risk, some biological evidence indicates that the quality factors for developmental injury may be quite different (Jiang et al. 1994). The radiation injury to developing hemopoiesis in exposed mouse embryo is shown in figure 4 for $250 \mathrm{mSv}$ exposures to gamma and alpha rays (assuming a quality factor of 20). The gamma ray result was obtained by linear interpolation of Jiang et al. data for $500 \mathrm{mSv}$. Jiang et al. have pointed out on the basis of their data that the conventional quality factor greatly underestimates the biological effects for this endpoint. Clearly a defined quality factor for developmental injury is needed if prenatal exposures to significant amounts of high LET radiations is expected.

Uncertainty in risk estimates for protection practice arises in part from uncertainty in the risk coefficient $\mathrm{k}$ resulting from extrapolation across nationalities, dose rate effectiveness, extrapolation to end of life... The changing risk coefficient due to extrapolation to end of life is shown in figure 5. Some factors which may change the risk coefficient in the future are the reevaluation of the W. W. II dosimetry and observations at the Chernobyl site. The current uncertainty in the low dose rate risk

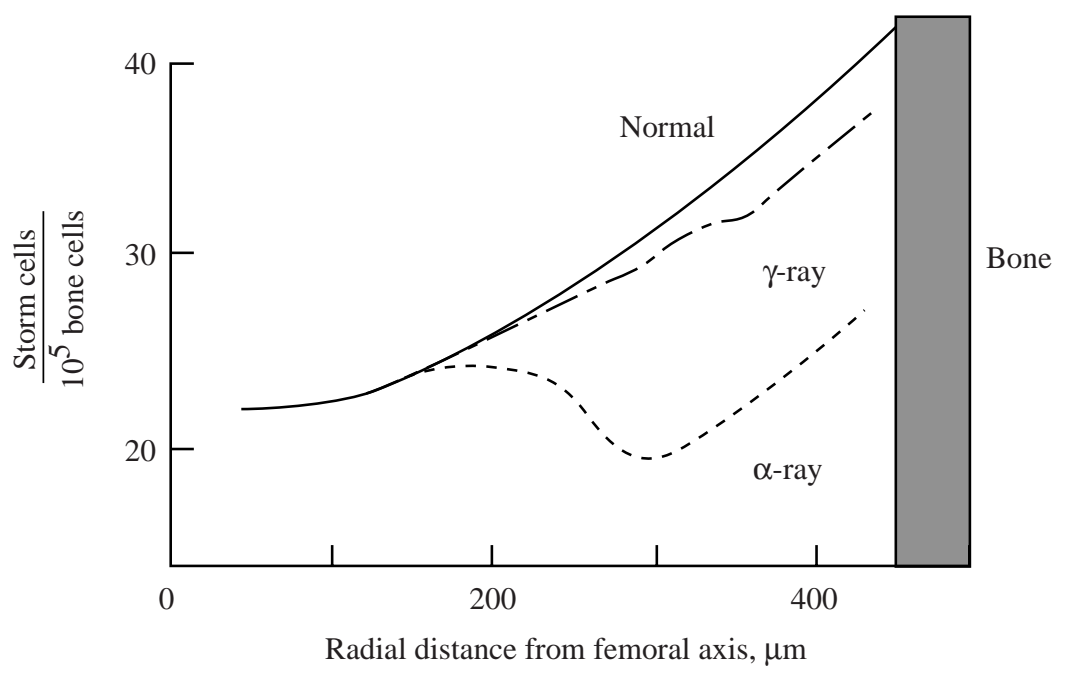

Figure 4. Damage to developing hemopoiesis from prenatal exposures of $250 \mathrm{mSv} \gamma$-rays and $\alpha$-rays $(Q=20)$ as observed by Jiang et al. (1994). 


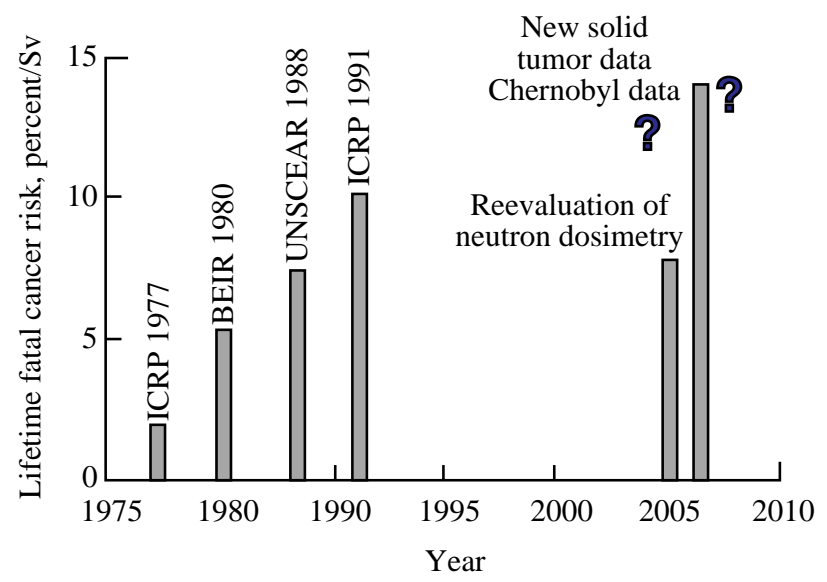

Figure 5. Trends in total cancer risk coefficient.

coefficient is a factor of two or three (NCRP 1989). Uncertainty in quality factor accounting for high LET effects is a factor of two to five (Curtis et al. 1995). Clearly, the uncertainty in controlling radiation induced risks is greatest as the fraction of the exposure containing high LET components increases.

Allowable exposures depend on the radiation risk coefficient, an assessment of acceptable risk levels, the exposed individual's knowledge of the exposure, and relationship to the individual's possible benefit as related to the exposure. For example, exposure of the general public is kept low since they may not even be aware of the exposure and may not directly benefit. Such public exposures are limited to be on the order of natural background levels (ICRP 1991). Those occupationally exposed derive a direct benefit from their work activity and are informed of their exposures. Occupational exposure levels are limited to risk levels comparable to risk of accidental death in moderately safe industries. Astronaut annual exposures may be quite high since they are informed, receive benefit from their occupation, start careers in mid-life, and are limited to a short career duration so that their lifetime risks are comparable to career lifetime risks of death in moderately safe industries. Pregnancy is a separate issue since the exposed individual is highly sensitive, receives no direct benefit, and is allowed to be exposed by decision of the parent. The current regulatory limits and proposed new limits are shown in table 1.

In the remainder of this paper, we will normally use the effective dose equivalent $\mathrm{H}_{\mathrm{E}}$ which is the sum of dose equivalent to specific tissues 
Table 1. Current and Projected Maximum Allowable Exposure Limits

\begin{tabular}{lcccc}
\hline & \multicolumn{4}{c}{ Maximum allowable exposure, mSv } \\
\cline { 2 - 5 } & $\begin{array}{c}\text { Present } \\
\text { United States } \\
\text { Exposure condition }\end{array}$ & $\begin{array}{c}\text { Present } \\
\text { United States } \\
\text { 10 CFR Part 20 }\end{array}$ & $\begin{array}{c}\text { Proposed } \\
\text { NUREG/BR-0117 }\end{array}$ & $\begin{array}{c}\text { Proposed ICRP } \\
\text { NCR rep. 116 }\end{array}$ \\
\hline $\begin{array}{l}\text { Occupational: } \\
\text { Annual }\end{array}$ & a50 & 50 & 50 & 20 \\
Lifetime & {$[50($ Age-18)] } & - & b 10 x Age & - \\
Pregnancy (total) & 5 & 5 & - & $c_{2}$ \\
Pregnancy (monthly & - & - & 0.5 & - \\
Public: & & & 1 & 1 \\
Annual, many years & $\mathrm{d} 1$ & 1 & 5 & - \\
Annual, occasional & - & 5 & - & $c_{2}$ \\
Pregnancy (total) & - & 5 & 0.5 & - \\
Pregnancy (monthly) & - & - & & \\
\hline
\end{tabular}

$\mathrm{a}_{\text {Not to exceed }} 30 \mathrm{mSv}$ in any quarter year.

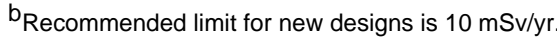

${ }^{\mathrm{c}}$ Abdomen surface for $\mathrm{X}$-rays, $1 \mathrm{mSv}$ in utero.

$d_{5} \mathrm{mSv}$ allowed with prior approval of NRC. 
times appropriate tissue weighting factors as related to the sensitivity of those tissues to fatal cancer as

$$
\mathrm{H}_{\mathrm{E}}=\Sigma_{\mathrm{T}} \mathrm{W}_{\mathrm{T}} \mathrm{H}_{\mathrm{T}}
$$

where $\mathrm{W}_{\mathrm{T}}$ is the tissue weighting factor for specific tissues derived from the W. W. II survivor's distribution of fatal cancers as given in table 2 and $\mathrm{H}_{\mathrm{T}}$ is the tissue dose equivalent.

\section{Terrestrial Background Exposures}

The term terrestrial background exposure is used here in the sense that these exposures are the normal result of everyday living in our present culture.

Primordial matter consists of a vast array of elemental components, many of which were unstable to radioactive decay and have long since disappeared in the 4.5 billion years of earthly existence. Only those primordial elements with unusually long decay times (U-238, Th-232, U235, Rb-87, and K-40) remain within the Earth's crust (Halliday 1962). These are the principal sources of exposure on the Earth's surface. There are three main decay chains headed by the long lived isotopes U238, Th-232, and U-235 which decay by sequential emission of alpha,

Table 2. Population Average Tissue Weighting Factors, WT (ICRP 1991)

\begin{tabular}{lc}
\hline Tissue or organ & $\mathrm{W}_{\mathrm{T}}$ \\
\hline Gonads & 0.20 \\
Bone Marrow (red) & 0.12 \\
Colon & 0.12 \\
Lung & 0.12 \\
Stomach & 0.12 \\
Bladder & 0.05 \\
Breast & 0.05 \\
Liver & 0.05 \\
Oesophagus & 0.05 \\
Thyroid & 0.05 \\
Skin & 0.01 \\
Bone surface & 0.01 \\
Other & 0.05 \\
\hline
\end{tabular}


beta, and gamma rays. The rates of decay within these chains are dominated by the lifetime of the longest lived isotopes at the head of the chain. A fourth decay chain Np-237 exists but was of sufficiently short decay time to have since disappeared from the Earth's environment. The emitted particles are in order of increasing range in matter as alphatens of micrometers, beta-few centimeters, and gamma-many meters. Unless internalized, only the gamma rays are of consequence in human exposures. A detailed summary of terrestrial exposures is given in NCRP Report 93 (1987).

Among the decay products of these radioactive chains is the noble gas radon which can become airborne and inhaled (along with its airborne decay products) resulting in exposures of lung tissues. Rn-222 produced in the U-238 decay sequence is the main source of such exposures although $\mathrm{Rn}-220$ from the Th-232 sequence makes non-negligible contributions. Radon related exposures are mainly through alpha emission and the bronchial epithelium is primarily exposed. Even then the main exposures result from breathing the trapped air within buildings and depends on location and construction techniques. The US average annual radon decay effective dose equivalent to lung tissues is given in table 3 as $2 \mathrm{mSv}$ and consists of high LET alpha particles with an assumed quality factor of 20 . Note that the lung tissue dose equivalent is larger than the effective dose equivalent since they differ by the lung weighting factor (table 2).

The other natural sources in table 3 consist of internal exposures from naturally occurring radionuclides and external exposures from gamma rays and cosmic rays. The most important internal emitters are K-40 beta rays and $\mathrm{Pb}-210$ and $\mathrm{Po}-210$ alpha emitters. Other primordial and cosmogenic radionuclei make only modest contributions to internal exposures. The external exposures are made-up from primordial radionuclides through gamma ray emission and a nearly equal contribution from cosmic radiation. These external exposures vary by a factor of two and more depending on location. Approximately two-thirds of these natural exposures other than radon are of low LET and the remaining third is mainly alpha emitting internal sources. The entire US population $(230,000,000$ in 1980) is exposed to this natural background and most individuals are exposed to within a factor of two of the average levels given in table 3 .

Consumer products are a second source of exposures for an estimated $120,000,000$ individuals in 1980. These include Pb-210 and Po-210 from tobacco smoking and sources in domestic water, building materials, and 
Table 3. U.S. Average Annual Background Effective Dose Equivalent (1980). (NCRP 1987)

\begin{tabular}{lcccc}
\hline Source & $\begin{array}{c}\text { Number exposed } \\
\text { (thousands) }\end{array}$ & $\begin{array}{c}\text { Average } \mathrm{H}_{\mathrm{E}} \\
(\mathrm{mSv})\end{array}$ & $\begin{array}{c}\text { Low LET } \\
(\mathrm{mSv})\end{array}$ & $\begin{array}{c}\text { High LET } \\
(\mathrm{mSv})\end{array}$ \\
\hline Natural & 230,000 & $2.0^{\mathrm{a}}$ & - & 2.0 \\
$\quad$ Radon & 230,000 & 1.0 & 0.69 & 0.31 \\
$\quad$ Other & & & & - \\
$\begin{array}{l}\text { Consumer } \\
\quad \text { Products }\end{array}$ & 120,000 & $0.005-0.13$ & $\sim 0.1$ & - \\
Medical & & & & - \\
$\quad$ Diagnostic X-ray & 180,000 & 0.39 & 0.39 & - \\
$\quad$ Nuclear Medicine & 7,400 & 0.14 & 0.14 & - \\
\hline arronchial Epithelium & & & &
\end{tabular}

a Bronchial Epithelium 
combustion products. Televisions, luminous watches, airport inspection, nuclear power ... provide little contribution to the general background. More important than consumer products are medical diagnostic X-ray exposures which are about half the natural background exposure excluding radon (see table 3 ). A smaller contribution comes from nuclear medicine. Consumer products and medical exposures are mainly from low LET components.

With the exception of the exposure of lung tissues with radon, the background exposures are dominated by low LET dose equivalents. Only a small fraction of exposure of most body tissues are by high LET alpha particles associated with a few specific tissues and internal emitters.

\section{Terrestrial Occupational Exposures}

Typical exposure of any individual within the US population from the several background sources in table 3 are within a factor of two of the average values shown. In addition to these exposures, there are those whose work activity result in an occupational radiation hazard. The number of individuals for whom occupational exposures are part of the workday have increased dramatically with developing technology from 216,000 in 1958 to 1.1 million in 1975 to an estimated 1.3 million in 1980 . The estimated average exposure for this class of people had declined from $2.4 \mathrm{mSv}$ to $1.1 \mathrm{mSv}$ over the same period. Typically half of the identified radiation workers had only negligible exposures so that the average of those with significant exposures was $4.8 \mathrm{mSv}$ in 1958 dropping to $2.2 \mathrm{mSv}$ in 1980 . The remainder of the radiation workers experienced only (or nearly) background levels as typified by table 3 . Note that the average occupational effective dose equivalent is on the order of the background levels in table 3. Even so there are a few radiation workers who are near maximal exposure levels in table 1 but have only small impact on averages due to their small number. Most individual radiation worker exposures in 1980 are within a factor two of the $2.2 \mathrm{mSv}$.

The occupational exposure distributions are given in table 4. Not shown in table 4 are those in each category who had little or no exposure and were nearly of equal numbers of individuals shown in each category. Also not shown in table 4 are the exposures of air crews which will be discussed in the next section. Among the most exposed terrestrial radiation workers are miners at $8.4 \mathrm{mSv}$ resulting mainly from high LET 
Table 4. U.S. Average Annual Occupational Effective Dose Equivalent (1980). (NCRP 1987)

\begin{tabular}{ccccc}
\hline Category & $\begin{array}{c}\text { Number exposed } \\
\text { (thousands) }\end{array}$ & $\begin{array}{c}\text { Average } \mathrm{H}_{\mathrm{E}} \\
(\mathrm{mSv})\end{array}$ & $\begin{array}{c}\text { Low LET } \\
(\mathrm{mSv})\end{array}$ & $\begin{array}{c}\text { High LET } \\
(\mathrm{mSv})\end{array}$ \\
\hline Medical & 277 & 1.5 & 1.5 & - \\
Industry & 156 & 2.4 & 2.4 & - \\
Nuc. Fuel Cyc. & 91 & 6.0 & 6.0 & - \\
Government & 117 & 1.1 & 1.0 & $<0.1$ \\
DOE Contr. & 81 & 2.8 & 2.0 & 0.8 \\
Miners & 10 & 8.4 & 1.2 & $7.2^{\mathrm{a}}$ \\
Other & 150 & 1.9 & 1.9 & - \\
\hline aBronchial Epithelium & & & &
\end{tabular}


inhaled radon released in the mining operations and these exposures are limited to lung tissues. The next most exposed group is for those involved in the nuclear fuel cycle processing mainly driven by the nuclear weapons industry. The most significant exposure of the broadest array of body tissues by high LET components is for the 81,000 DOE contractors. DOE contractors received 40 percent of their exposure from high LET components (mainly low energy neutrons), the other nearly 1.3 million workers had little high LET exposures (mainly from background and not from occupational exposures). Consequently, the health risks of most occupational exposures are among the best known radiation risks.

\section{Past Commercial Air Transportation Studies}

When the possibility of high-altitude supersonic commercial aviation was first seriously proposed, Foelsche brought to light a number of concerns for the associated atmospheric radiation exposure due to penetrating cosmic rays (CR) from the galaxy (GCR) and the sun (SCR also referred to as solar particle events, SPE) including the secondary radiations produced in collision with air nuclei (Foelsche 1961, Foelsche and Graul 1962). Subsequently, a detailed study of the atmospheric ionizingradiation components at high altitudes was conducted from 1965 to 1971 at the Langley Research Center (LaRC) by Foelsche et al. (1974). Prior to that study the role of atmospheric neutrons in radiation exposure was generally regarded as negligible (ICRP 1966). The LaRC studies revealed the neutron radiation to be the major contributor to aircraft GCR exposure. Still the exposure levels were comfortably below allowable exposure limits for the block hours typical of airline crews of that time except during a possible solar particle event (less than 500 block hours were typical of the 1960's although regulations allow up to 1000 hours).

The Langley flight package consisted of a 1-10 MeV neutron spectrometer, tissue equivalent ion chamber, and nuclear emulsion for nuclear reaction rates in tissue and commissioned over 300 flights over most of the duration of solar cycle 20 on high altitude aircraft and balloons. Monte Carlo calculations (Lambiotte et al. 1971) for incident GCR protons were used to extend the neutron spectrum to high energies (figure 6). Also shown in figure 6 are the contributions to dose and dose equivalent from neutrons on individual energy decades. Over half of the dose is from neutrons above $10 \mathrm{MeV}$ and an accurate knowledge of the high energy neutron quality factors is critical to evaluation of dose equivalent. The fraction of the dose equivalent from neutrons is near one half as shown in figure 7. Additional high LET components come from 


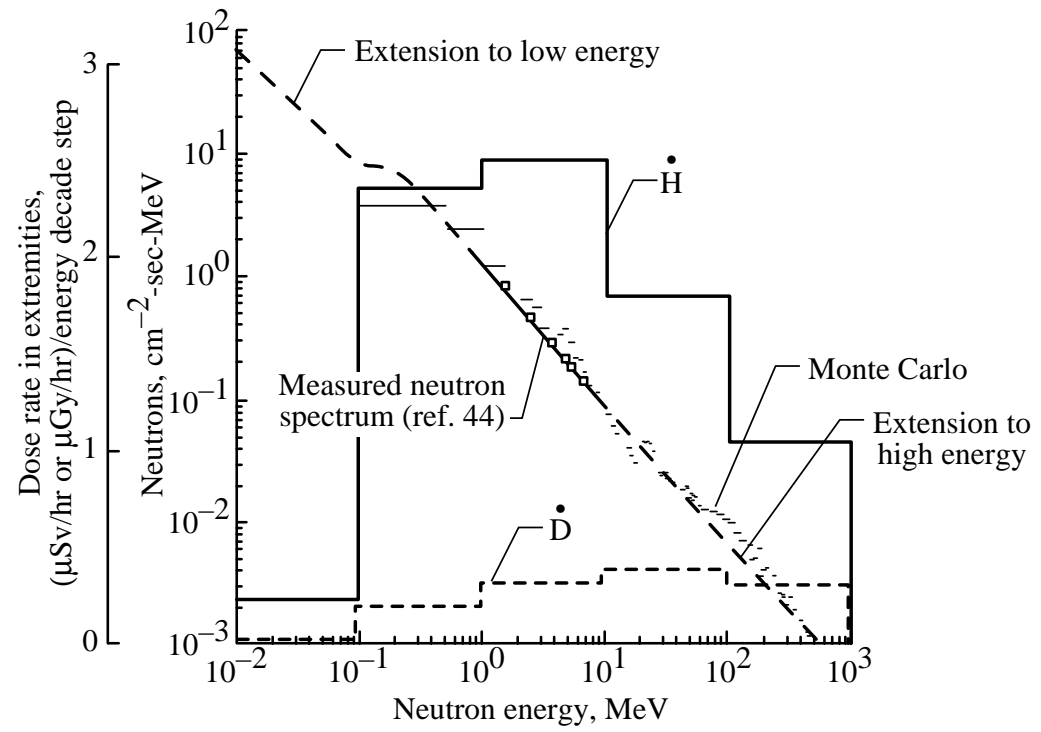

Figure 6. Neutron spectrum at $70,000 \mathrm{ft}$ over Ft. Churchill on August 3, 1965.

the nuclear reactions caused by the charged hadrons so that well over half of the exposures in commercial operations are from high LET events which leaves large uncertainties in the associated health risks even if the radiation levels are accurately known.

Uncertainty in background aircraft exposures. Although a consistent data set over much of the Earth's surface and most of solar cycle 20 has been measured by the Langley program, many of the individual components were not resolved due to instrument limitations at the time of measurement and the major portion of the neutron spectrum depended on theoretical calculations for proton interactions with the atmosphere. Hewitt et at. (1978) measured the neutron spectrum using a Bonner sphere set up at subsonic altitudes and analyzed the data assuming a simple power spectrum and confirmed the importance of the high energy neutrons but left the exact nature of the spectrum uncertain due to limitations of the analysis methods. Ferenc Hajnal of the Environmental Measurements Laboratory developed new analysis techniques for unfolding Bonner sphere neutron spectral data and found important structural features in Hewitt's data near $100 \mathrm{MeV}$ (see figure 8) that have important implications for aircraft exposures (Hajnal and Wilson 1991, 1992). A quick survey of published atmospheric neutron spectra shows considerable uncertainty in our knowledge (figure 9) and the impact of these uncertainties are shown in figure 10 . In figure 10 are 

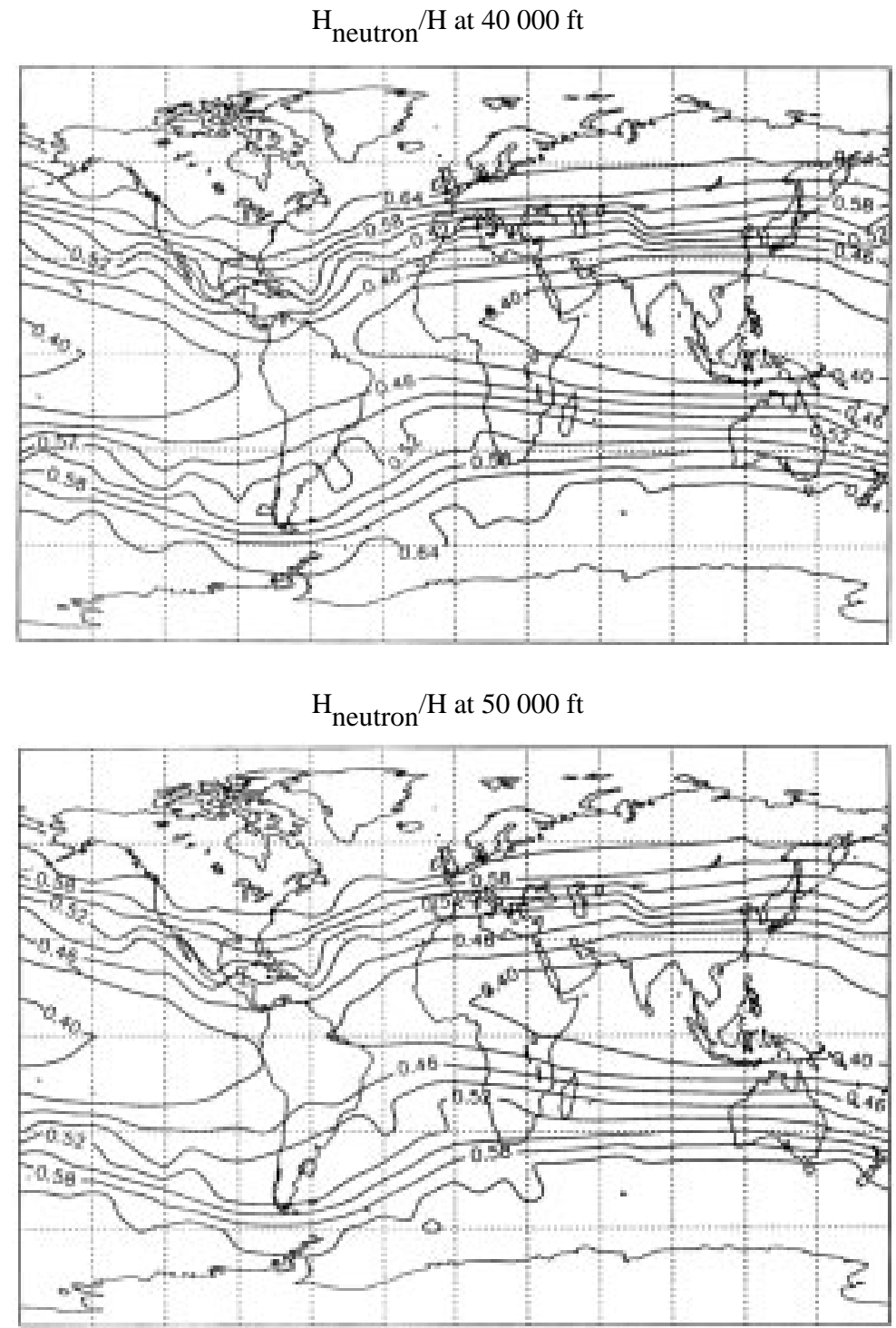

Figure 7. Fraction of dose equivalent due to neutrons at solar minimum (1965). 


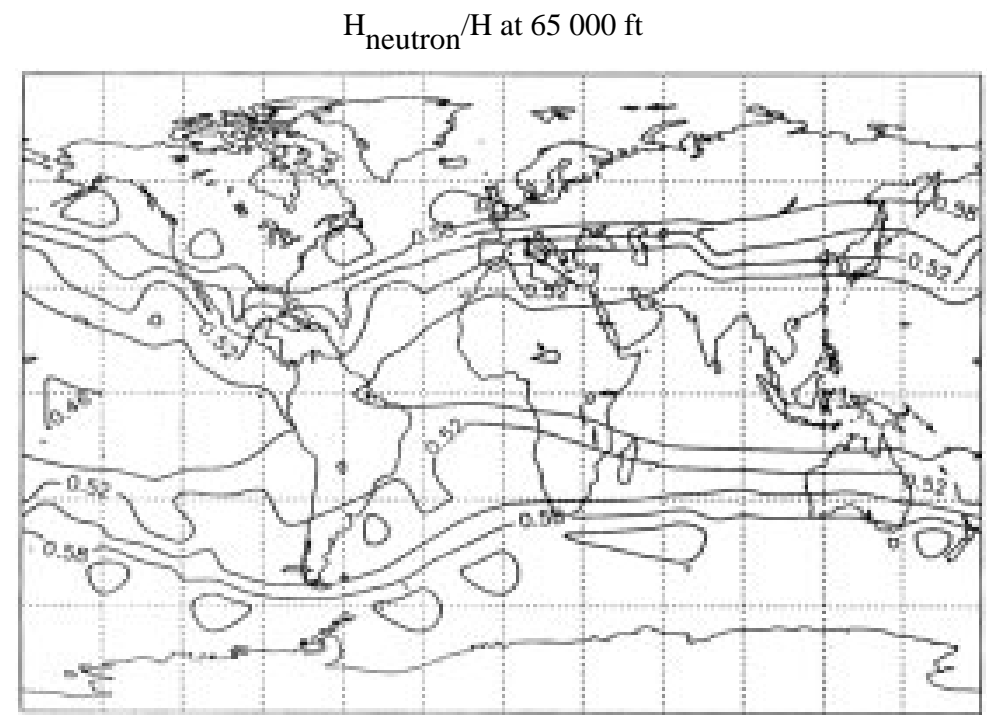

$\mathrm{H}_{\text {neutron }} / \mathrm{H}$ at $73000 \mathrm{ft}$

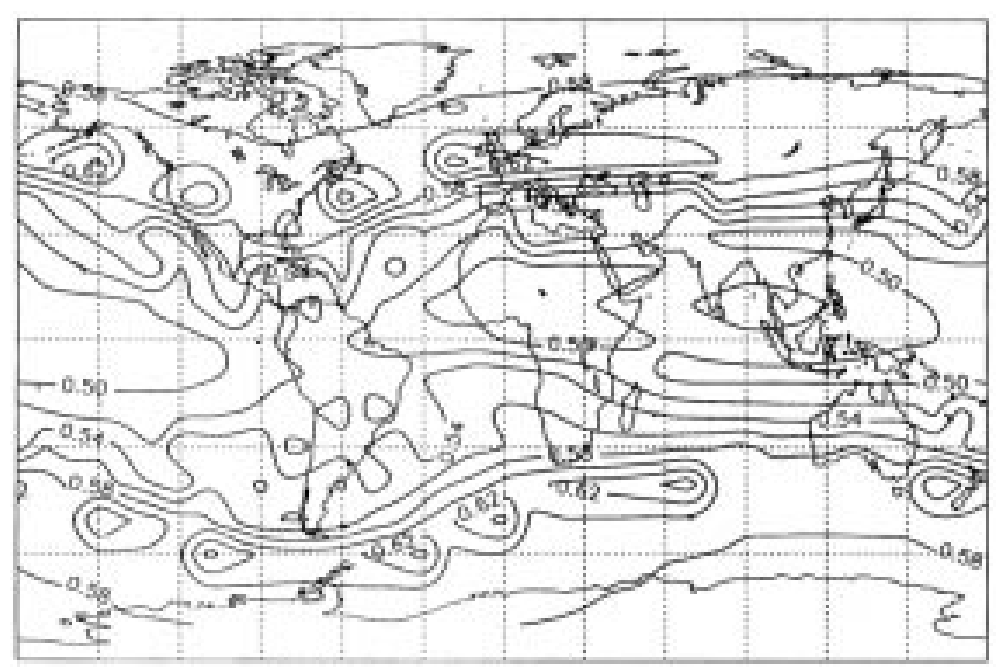

Figure 7. continued. 


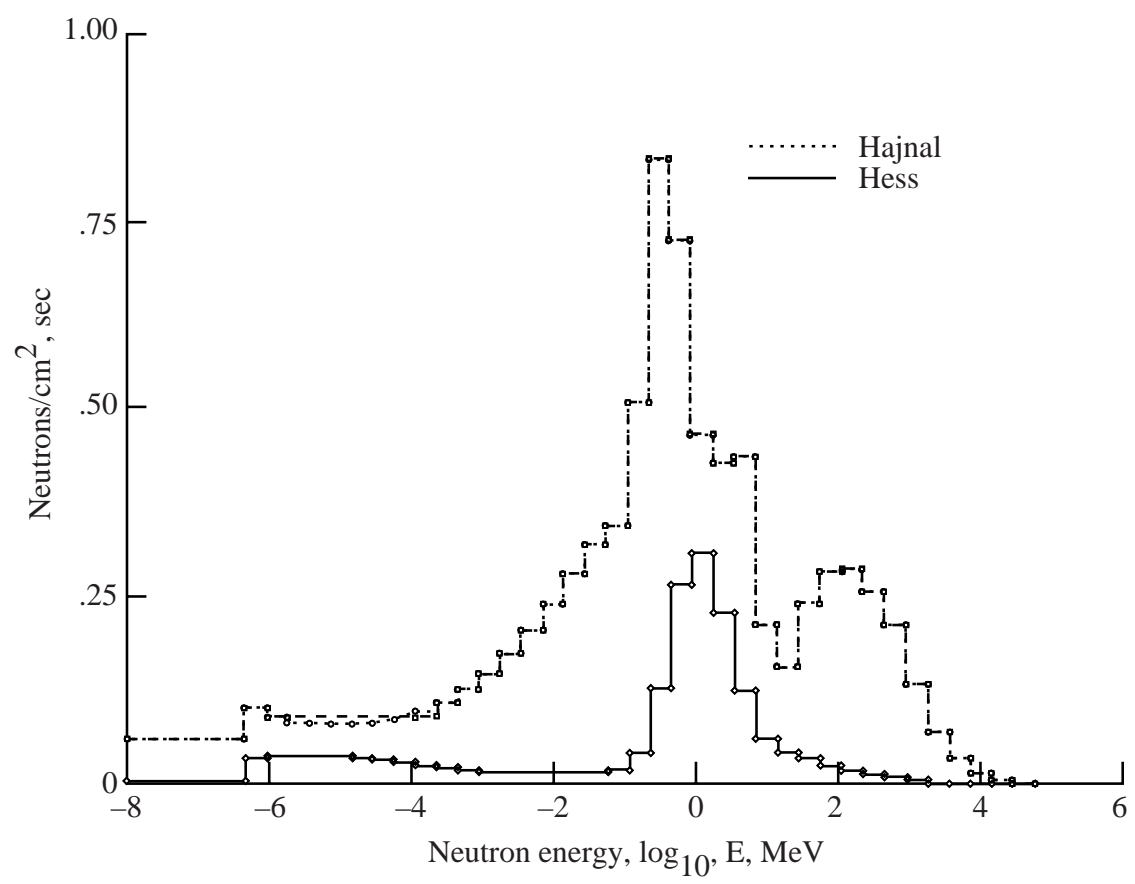

Figure 8. Hajnal unfolded neutron spectrum from Hewitt data measured at $17.46^{\circ} \mathrm{N}$ at $23.5 \mathrm{~km}$ compared to Hess spectrum.

shown annual crew dose equivalents for three high latitude commercial trajectories and the associated uncertainties. The annual dose equivalent depends on the number of block hours worked. The High Speed Civil Transport (HSCT) trajectories assume flight at subsonic altitudes except over large bodies of water. It is clear from these results that rather large exposures can be expected depending on working conditions and uncertainty in the neutron spectra is critical to limitation of individual exposures (Wilson et al. 1995b, NCRP 1996). In addition to exposures in actual flight operations, added exposure is due to off duty flights in returning to a home base estimated by some to be twenty percent of actual block hours. It may also be surmised from the results in figure 10 in comparison to table 3 that aircrew working on the most commonly traveled high latitude routes and even modest number of block hours are among the most highly exposed occupational groups. Furthermore, the exposure levels have large uncertainties and the associated risk factors are also uncertain since the exposures are dominated by high LET components. Subsequent studies by Allkofer and Heinrich (1974) showed that the penetrating GCR contribute a high LET 


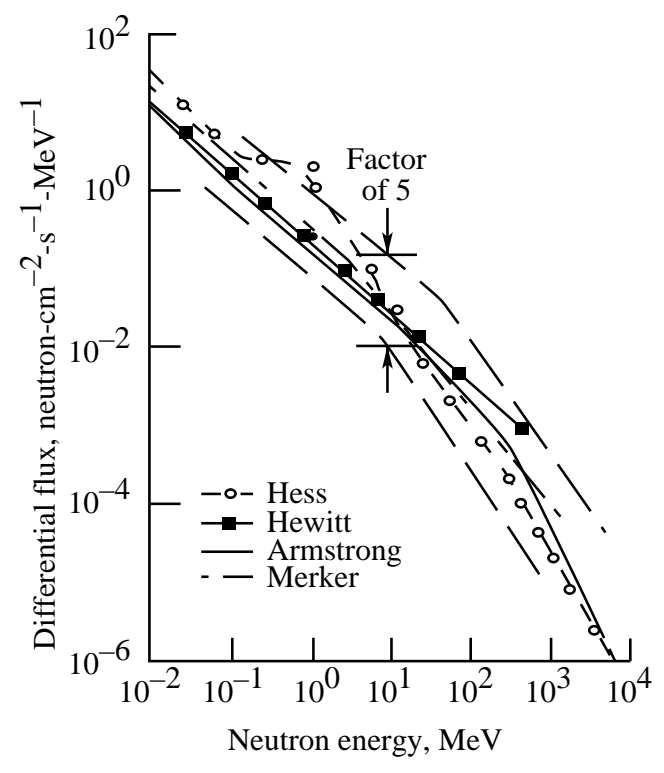

Figure 9. Neutron spectrum measured by Hewitt and Hess with calculations by Armstrong and Merker.

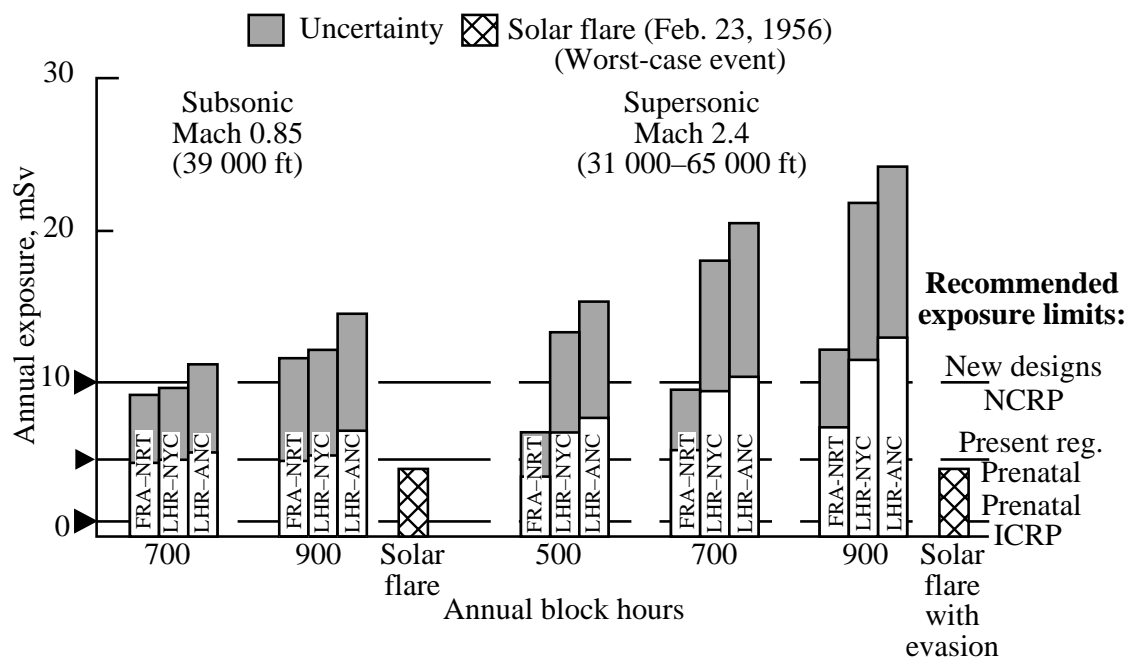

Figure 10. Annual crew exposures for subsonic and Mach 2.4 flights along specific air routes for assumed number of block hours. 
event per gram of tissue per month which may have consequence in early prenatal exposure.

Solar particle event exposures. The only solar particle events of interest are those capable of ground level observations with ion chambers (figure 1) or neutron monitors. The rate of occurrence of such events (Shea and Smart 1993) are shown in figure 11. The ground level events vary greatly in intensity and only the most intense events are important to high altitude aircraft protection. The largest ground level event yet observed occurred on Feb. 23, 1956 in which neutron count rates rose to 3,600 percent above background (figure 12). Two of the afore mentioned over 300 flights were made out of Fairbanks, Alaska during the event of March 30-31, 1969 with results shown in figure 13. If the ground level increase for the March 1969 event is used to scale other historical ground level events, we conclude that high levels of radiation exposure were present at aircraft altitudes in the past. The proton spectra for the Feb. 1956 event are imperfectly known but upper and lower bounds estimated by Foelsche result in dose equivalent rates from Monte Carlo calculations in reasonable agreement with those derived from simply scaling the March 1969 data. The Monte Carlo results are
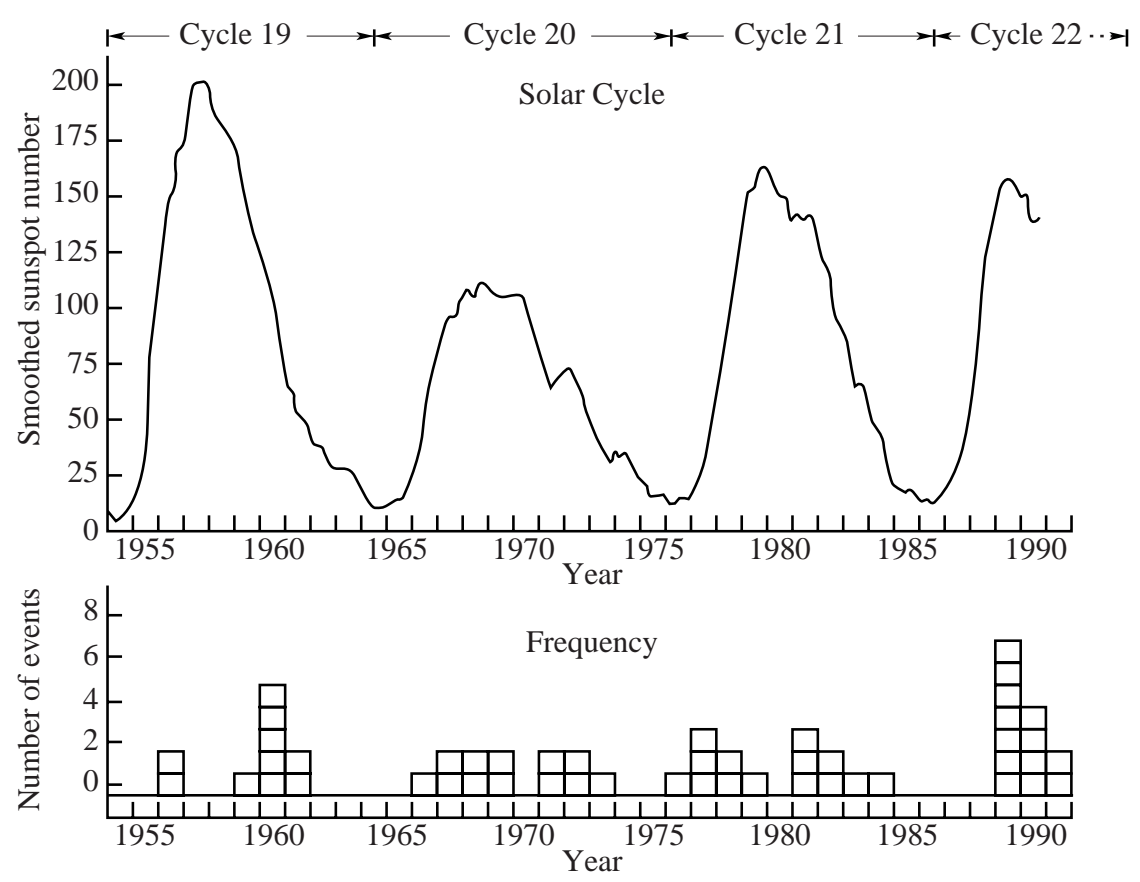

Figure 11. Temporal distribution of ground level solar particle events for the past 40 years. (Shea and Smart 1993). 


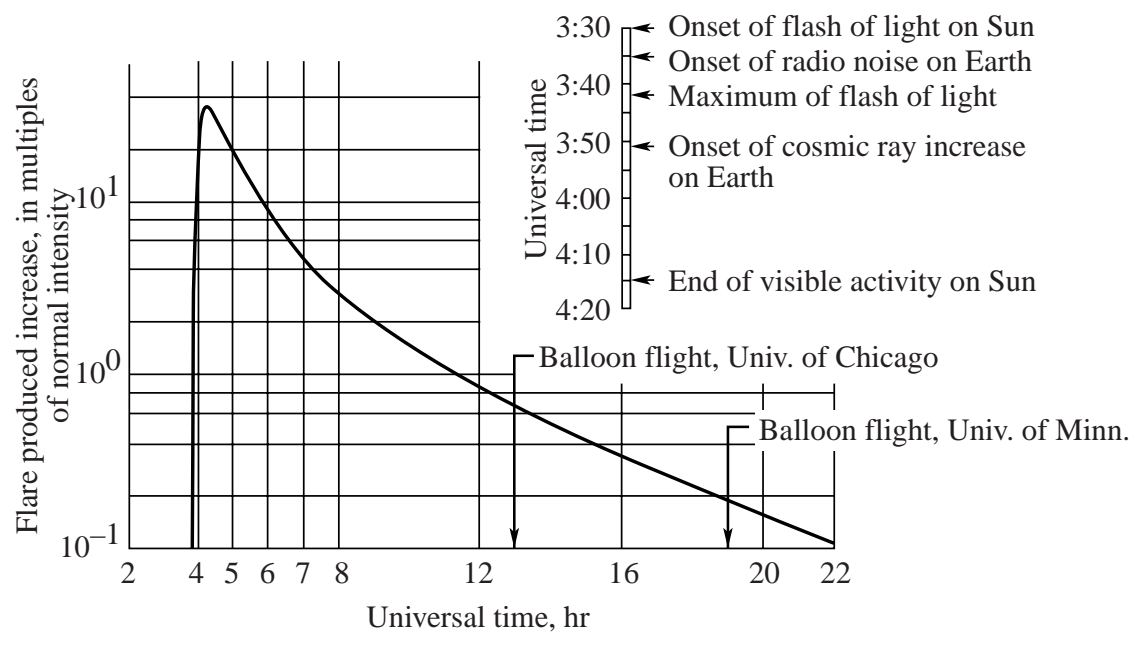

Figure 12. Ground level neutron monitor event seen at Durham, NH on Feb. 23, 1956. (Schaefer 1959).

shown in figure 14 as calculated by the Langley code (Wilson et al. 1970) and Armstrong et al. (1969) at Oak Ridge National Laboratory using the High Energy Transport Code (HETC). The results in the figure use the maximum surface dose equivalent conversion factors for a $30-\mathrm{cm}$ tissue slab geometry. Dose equivalent averaged over the $30-\mathrm{cm}$ slab are approximately a factor of 2-3 lower for solar particle events (Foelsche et al. 1974). It was clear from these results that exposures to crew and passengers on high latitude routes of the SST flying at 58 $\mathrm{g} / \mathrm{cm}^{2}$ would be unacceptable unless decent to subsonic altitudes was possible to minimize exposures during such a large event.

The main concern of these early studies was the potential prenatal injury in high altitude flight especially during such a possible large solar event since crew and passengers included women of child bearing age. An advisory committee to the Federal Aviation Administration (FAA) recommended that a satellite early-warning/monitoring system be established, active onboard monitoring devices be included in the aircraft design, and that operational procedures be developed to insure that exposures on a given flight be limited to $5 \mathrm{mSv}$ (anon. 1975). 


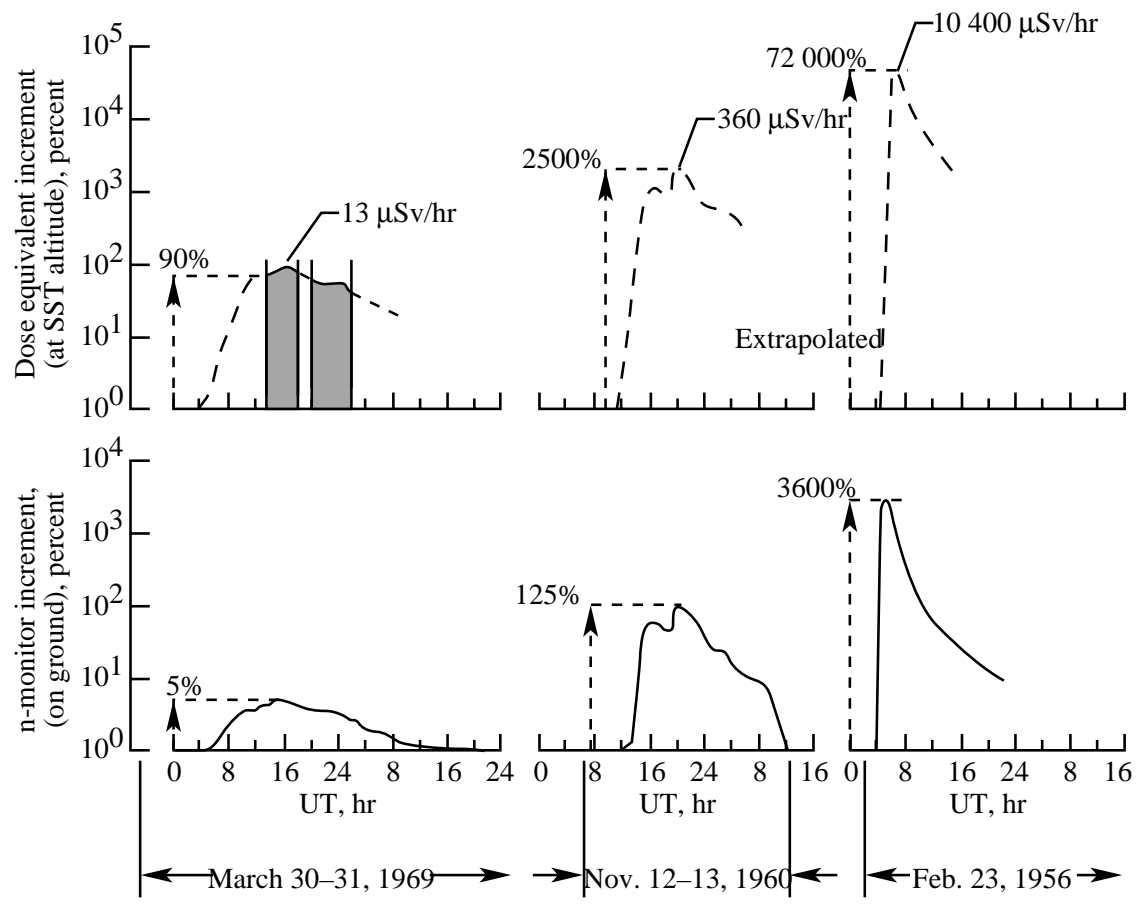

Figure 13. Energetic solar events measured on the ground and at SST altitude.

Atmospheric radiation model. A computer program called the Galactic Radiation Exposure Program (GREP) was written by S. B. Curtis and published by the Boeing Co. (1969). The exposure estimates using the ion chamber data of Neher (1961) and Neher and Anderson (1962) and the neutron data of W. N. Hess et al. (1961). The code was modified for various aircraft trajectories between city pairs by Wallace and Sandhous (1978). The inadequacy of the data base used was reviewed by Foelsche (1961) and Friedberg and Neas (1980). An alternative code was written by O'Brien and McLaughlin (1972). A comparison of these codes with a model derived from the Langley data base is shown in figure 15 adapted from Friedberg and Neas (1980). Note, the curve HASL (now referred to as the LUIN code) is the O'Brien and McLaughlin model, ACRE is the Wallace and Sandhous revised Boeing model, and $\mathrm{LRC}$ are the measured data of the Langley flights and the basis of the first generation atmospheric ionizing radiation (AIR) model. All of these results are based on older dosimetric relationships using the older quality factors. The HASL and ACRE results are for a lower latitude (55 degrees north) than the LRC results (69 degrees north) and their 


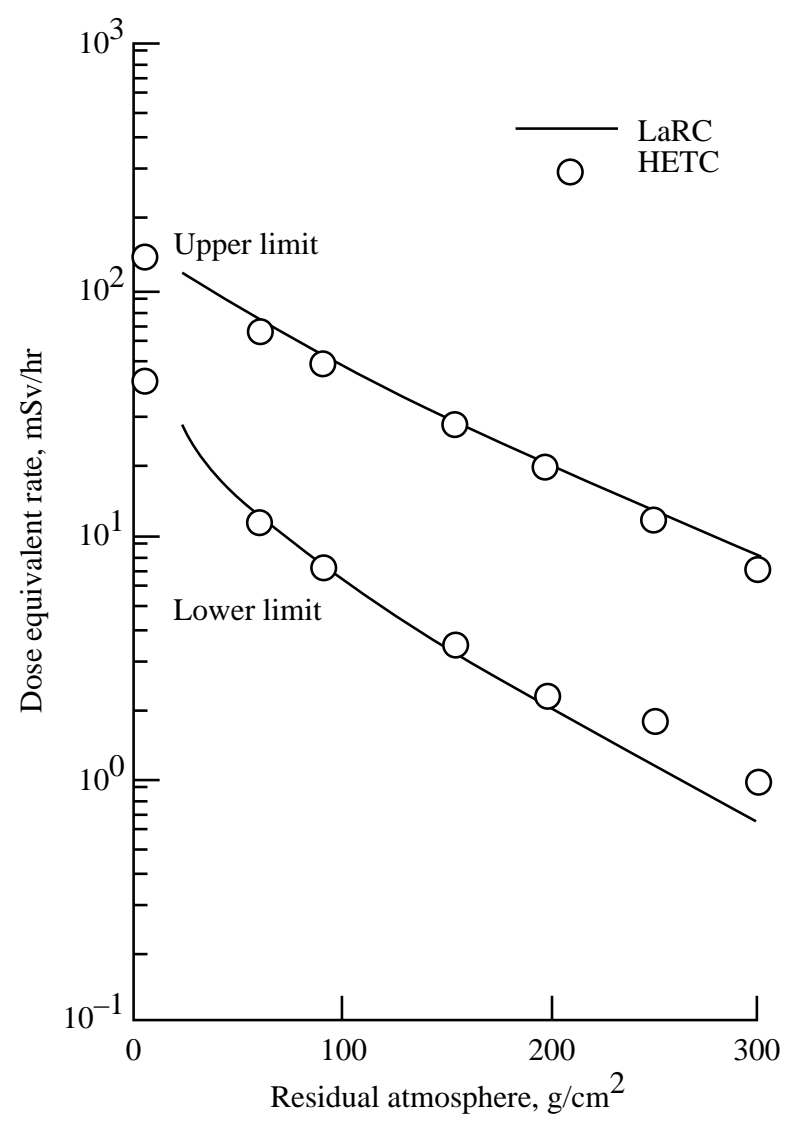

Figure 14. Calculated upper and lower limits for dose equivalent rate at high latitude for the Feb. 23, 1956 event.

results would be higher especially at the highest altitudes. There are obvious substantial differences in magnitude and altitude dependence. Two of the models depend on the Hess et al. (1961) neutron spectra which, as further study concludes, is misleading in its spectral distribution (see figures 8 and 9).

The quality factors in the AIR model were recently updated to the new ICRP recommendations and the global distributions at four altitudes are shown for solar minimum in figure 16 . The specifics of the dose contours are mainly determined by the geomagnetic field lines. The dip over the eastern US is due to the tilt of the magnetic north pole into Canada. This strongly affects the exposures for the popular routes from northern Europe to New York which occur mainly in the polar region. 


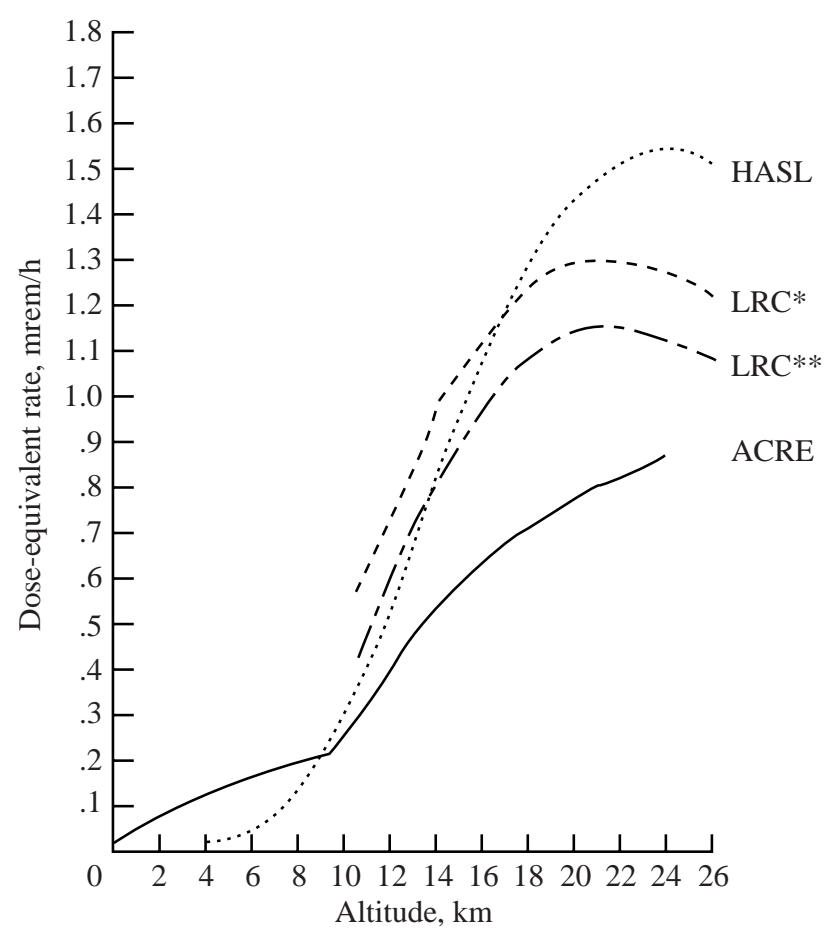

Figure 15. Atmospheric radiation levels as a function of altitude averaged over solar cycle: HASL and ACRE at $55^{\circ} \mathrm{N}, \mathrm{LRC}$ at $69^{\circ} \mathrm{N}$. LRC $^{*}$ for extremities, LRC ${ }^{* *}$ center of body. (Friedberg and Neas 1980)

The exposure levels vary by about a factor of two or more between solar maximum and minimum at the high latitudes as shown in figure 17. There is also a factor of two difference in exposure levels between flying subsonic and supersonic as seen in figure 16. Such variations could have an important impact on the management of aircrew exposures.

\section{Recent Commercial Air Transportation Studies}

Several factors have changed since those early studies: (A) the highly ionizing components are found to be more biologically damaging than previously assumed and the associated quality factors for fatal cancer have been increased (ICRU 1986, ICRP 1991); (B) recent studies on developmental injury in mice embryo indicate larger quality factors are required for protection in prenatal exposures (Jiang et al. 1994), (C) recent epidemiological studies (especially the data on solid tumors) and more recent A-bomb survivor dosimetry have resulted in higher 
$\mathrm{H}, \mathrm{mSv} / 1000 \mathrm{hr}$ at $40000 \mathrm{ft}$

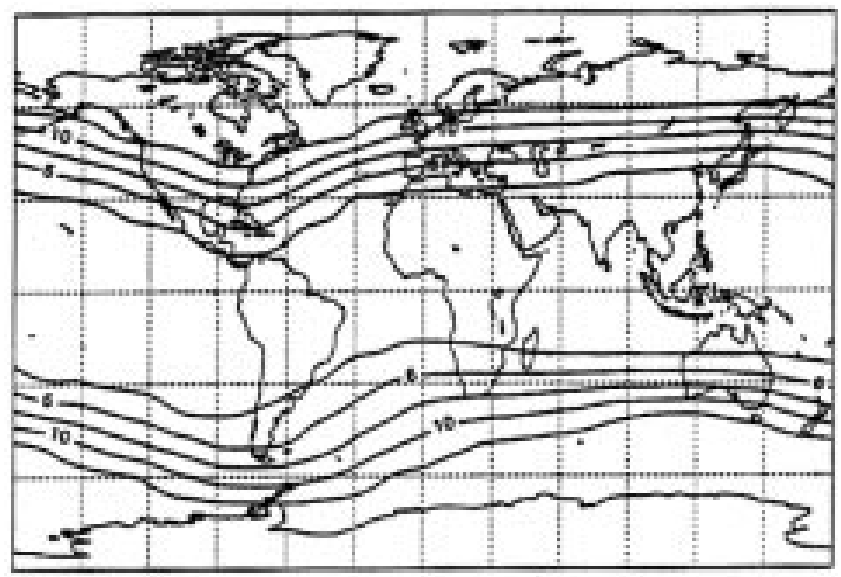

$\mathrm{H}, \mathrm{mSv} / 1000 \mathrm{hr}$ at $50000 \mathrm{ft}$

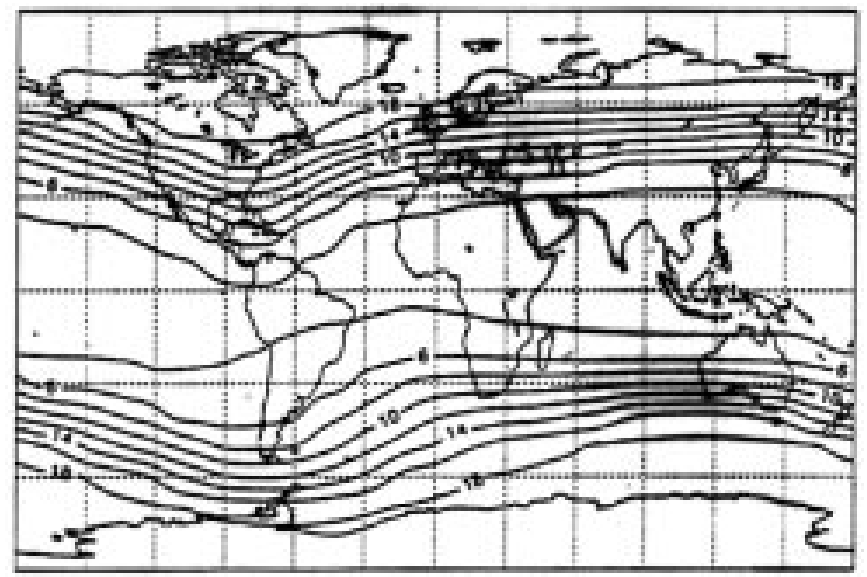

Figure 16. Background exposure levels in upper atmosphere at solar minimum.

radiation risk coefficients for $\gamma$ rays (UNSCEAR 1988, BEIR V 1990, ICRP 1991) resulting in lower proposed permissible limits (ICRP 1991, NCRP 1993); (D) "an urgent need is recognized for better estimates of the risk of cancer from low levels of radiation" (anon. 1993); (E) subsequent to deregulation of the airline industry, flight crews are logging greatly increased flight hours (Bramlett 1985, Wilson and Townsend 1988, Friedberg et al. 1989, Barish 1990); (F) a new class of 
$\mathrm{H}, \mathrm{mSv} / 1000 \mathrm{hr}$ at $65000 \mathrm{ft}$

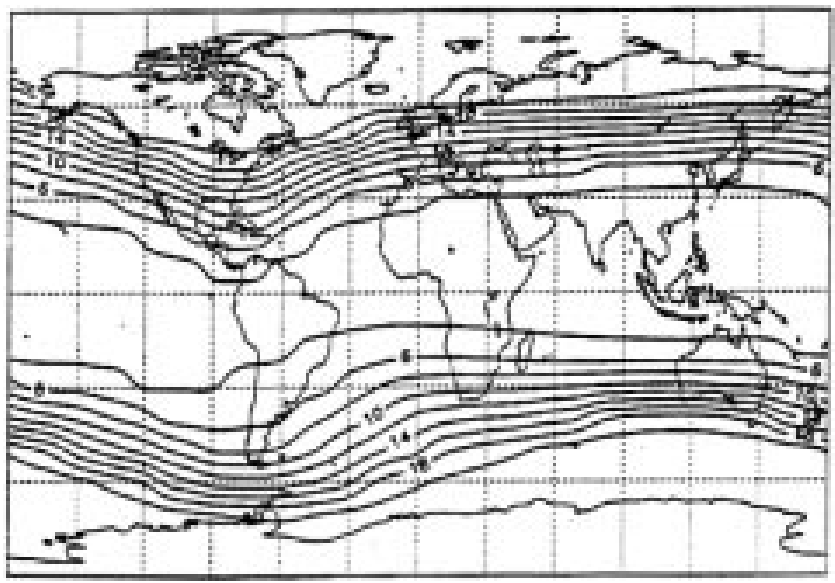

$\mathrm{H}, \mathrm{mSv} / 1000 \mathrm{hr}$ at $73000 \mathrm{ft}$

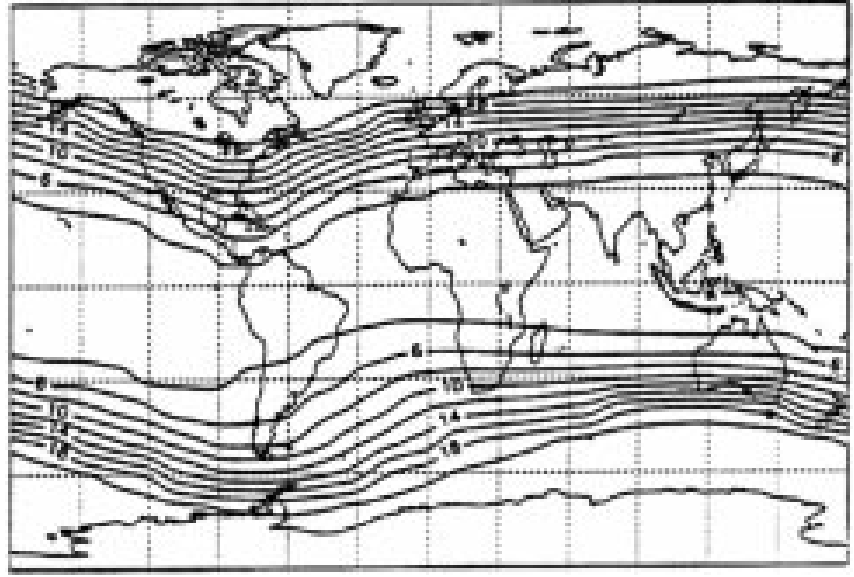

Figure 16. Continued.

long haul commercial aircraft is being developed on which personnel for two crew shifts will be simultaneously aboard a single flight leading to increased exposures for a fixed number of flight duty hours (Lebuser 1993); (G) airline crew members are now classified as radiation workers (McMeekin 1990, ICRP 1991); and (H) NASA is developing technology for a Mach 2.4 High Speed Civil Transport (HSCT) to begin service in the twenty-first century. In recognition of the potential impact of several of these factors on present day crew exposures, the Commission of the 
$\left(\mathrm{H}_{\text {sol }}\right)_{\min } /\left(\mathrm{H}_{\text {sol }}\right)_{\max }$ at $40000 \mathrm{ft}$

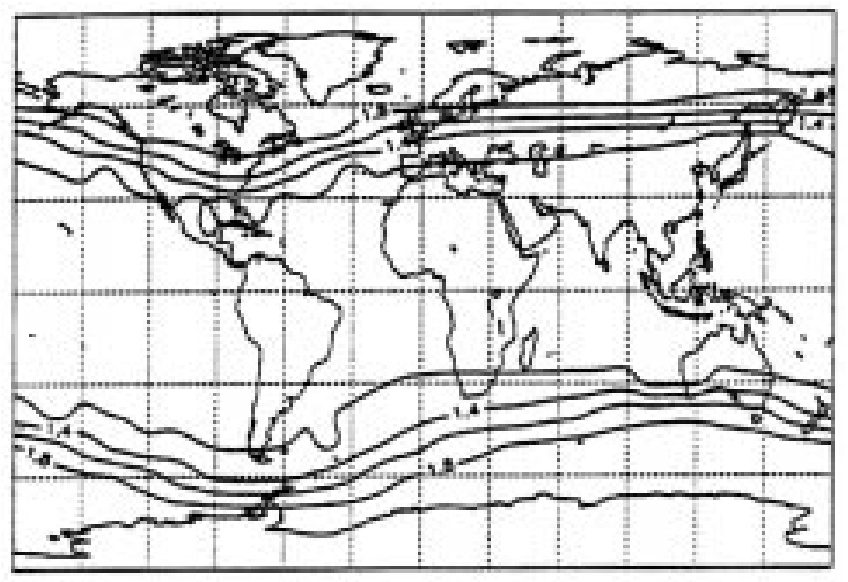

$\left(\mathrm{H}_{\mathrm{sol}}\right)_{\min } /\left(\mathrm{H}_{\mathrm{sol}}\right)_{\max }$ at $50000 \mathrm{ft}$

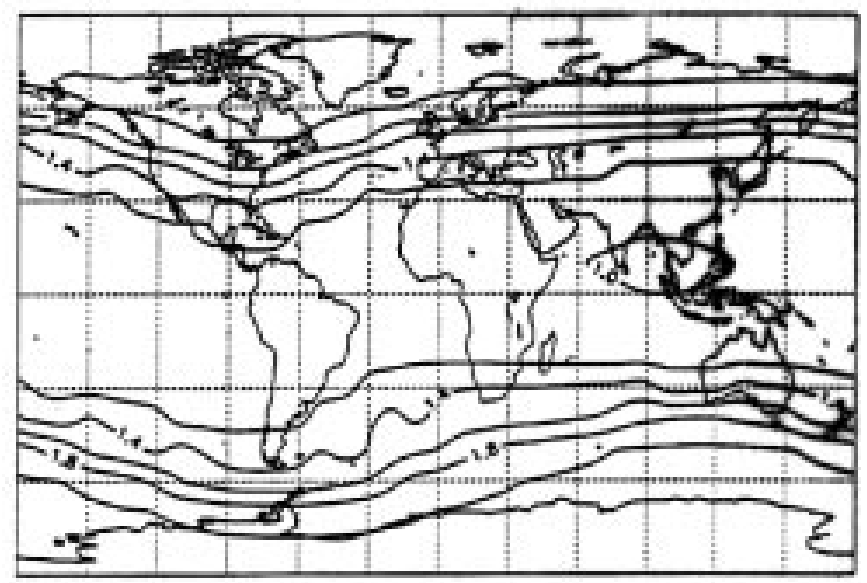

Figure 17. Maximum solar modulation ratio in atmospheric radiation levels.

European Communities organized a Workshop on Radiation Exposure of Civil Aircrew (Reitz et al. 1993). The workshop conclusions (mainly for subsonic exposures) are that the environment is not adequately known for reliable estimates of dose equivalent resulting mainly from uncertainty in the neutron spectra at high energies and a re-evaluation of the heavy ion component should be made. Finally, it is clear that the development of advanced high-speed commercial aircraft (HSCT) requires some attention to the past concerns of high-speed flight but in terms of current day knowledge and uncertainty in that knowledge (Wilson et al. 1995b). 
$\left(\mathrm{H}_{\mathrm{sol}}\right)_{\min } /\left(\mathrm{H}_{\mathrm{sol}}\right)_{\max }$ at $65000 \mathrm{ft}$

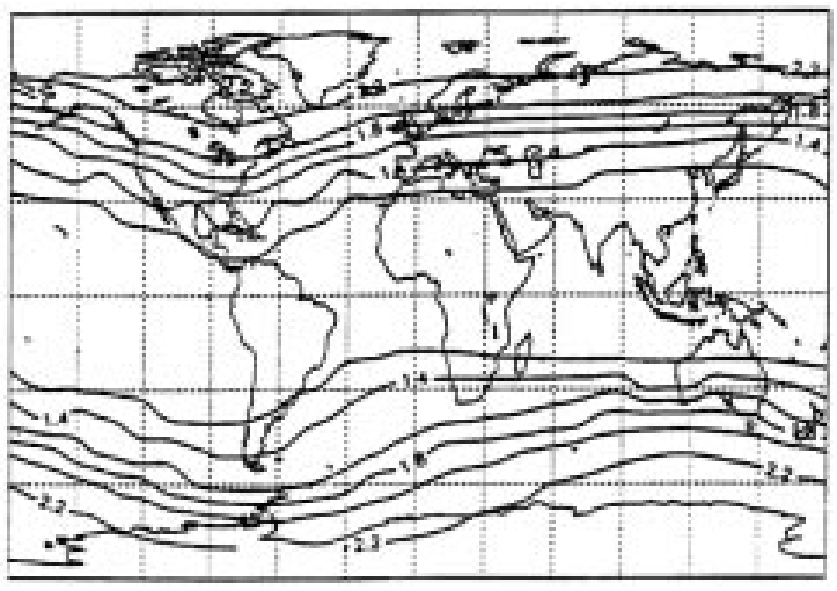

$\left(\mathrm{H}_{\mathrm{sol}}\right)_{\min } /\left(\mathrm{H}_{\mathrm{sol}}\right)_{\max }$ at $73000 \mathrm{ft}$

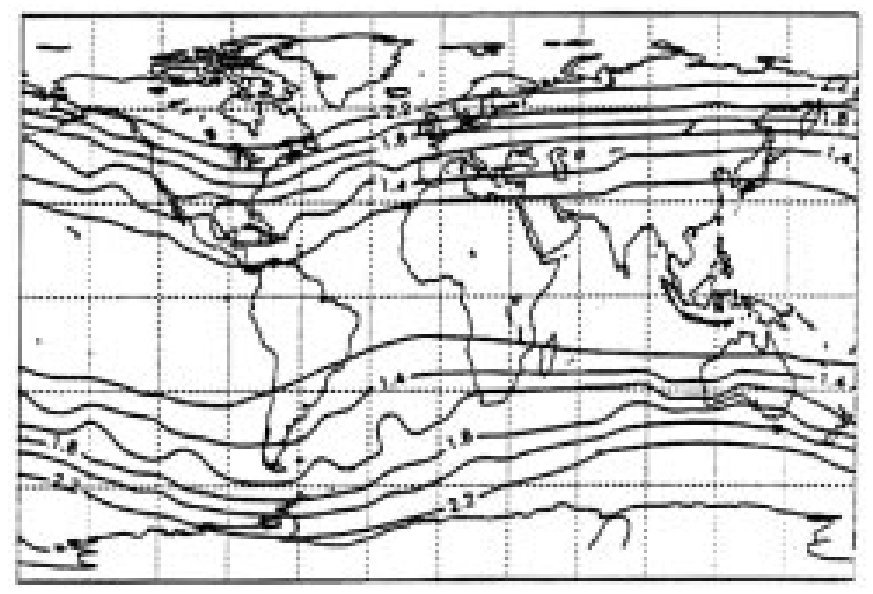

Figure 17. Continued.

Recently the International Civil Aviation Organization (ICAO) has recommended that "All aeroplanes intended to be operated above

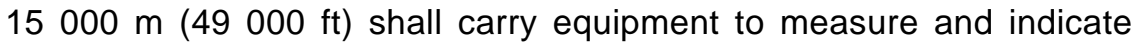
continuously the dose rate of total cosmic radiation being received (i.e., the total of ionizing and neutron radiation of galactic and solar origin) and the cumulative dose on each flight. The display unit of the equipment shall be readily visible to a flight crew member." (ICAO 1995). 
European Commission, Directorates General XI and XII. In response to the ICRP Publication 60 recommending that air crew members be classified as radiation workers and the significant lowering of recommended exposure limits, the European Commission first sponsored the Workshop on Radiation Exposure of Civil Aircrew (Reitz et al. 1993). Following the workshop, research has been funded through several groups including the formation of the EURADOS working group 11 to report on "The Radiation Exposure and Monitoring of Air Crew." Among the conclusions of the working group are that monitoring is not required for individuals whose expected exposures are less than $1 \mathrm{mSv}$ per year. On-board monitoring may be required where doses may exceed $6 \mathrm{mSv}$ per year with view to reducing individual exposures. Attention should be paid to additional controls to protect the embryo or fetus in the case of pregnancy. They also note that the $2 \mathrm{mSv}$ limit for dose to the abdomen during the remainder of a declared pregnancy recommended by the ICRP is not sufficient to keep dose to the embryo/fetus to $1 \mathrm{mSv}$ for the radiations present on aircraft (also see Wilson et al. 1995b). It would not be appropriate to classify any part of a civil aircraft as a controlled or supervised area. That ambient dose equivalent could be used as the operational quantity although a calculated effective dose equivalent could also be used. That aircrew and frequent flyers dose estimates could be made by folding route doses with flight rosters and records kept to ensure that exposures do not reach recommended limits. On-board monitoring may be required for aircraft operating above an altitude of $15 \mathrm{~km}$. The agreement between flight data and theoretical models are unsatisfactory and improved scientific data on different particles and their spectral distributions are required (McAulay et al. 1996).

NCRP Recommendations. NASA funded a study by the US congressionally chartered federal advisory agency, National Council Radiation Protection (NCRP), to make recommendations on radiation safety requirements for future HSCT operations. As a result of the higher expected exposures in high-altitude flight, the NCRP examined the data on atmospheric radiation and made the following (paraphrased) recommendations (NCRP 1996):

1. Additional measurements of atmospheric ionizing radiation components need to be conducted with special emphasis on high energy neutrons

2. A survey needs to be conducted on proton and neutron biological data on stochastic effects and developmental injury for evaluation of appropriate risk factors 
3. Methods need to be developed for avoiding solar energetic particles, especially for flight above $60,000 \mathrm{ft}$

4. A radiation protection philosophy and radiation protection guidelines need to be developed for commercial flights, especially at high altitudes of 50,000 to $80,000 \mathrm{ft}$

As clearly stated in the NCRP Commentary 12, we should seek to know the level of exposure of aircrew commensurate with those of other occupationally exposed groups. Clearly, these recommendations must be addressed before the HSCT enters service in order to ensure the safety of the crew and passengers. Only the first of these recommendations have so far been addressed.

Recent studies of background aircraft exposures. A study of the atmospheric neutron spectrum lead by $H$. Schraube of GSF in Neuherberg has been funded by the Directorate General XII. The experimental component consists of a Bonner sphere spectrometer with a ${ }^{3} \mathrm{He}$ proportional counter (Schraube et al. 1998) on a mountain top (Zugspitze). The theory part of the study uses the FLUKA code at the University of Siegen and the known cosmic rays incident on the atmosphere (only the multiple charged ions are assumed to be dissociated into constituents, Roesler et al. 1998). It is interesting to note that the structure expected from the analysis of Hajnal at $100 \mathrm{MeV}$ (figure 8) appears in both the measurements and the FLUKA calculation (see figure 18). Note that this feature is absent from the LUIN code which depended on the Hess spectrum for guidance as the LUIN code is not a fundamental calculation in that information outside the LUIN result is used to patch an answer into the final values (O'Brien and Friedberg 1994). The importance of the Schraube et al. (1998) result is that the neutron ambient dose equivalent is about a factor of two larger than that estimated using the LUIN code (Schraube et al. 1998) and the added contributions are from high energy neutron interactions with tissue nuclei resulting in an array of high LET reaction products at each collision event. Very little biological data exist on such radiations (Wilson et al. 1990).

Further studies were started at the Langley Research Center. An instrument package was developed in accordance with the NCRP recommendations through an international guest investigator collaborative project, thereby ensuring the availability of the numerous instruments required to measure the many components of the radiation spectra. Selection criteria included: (a) the instruments had to fit within the cargo bay areas of the ER-2 airplane and be able to function in that 


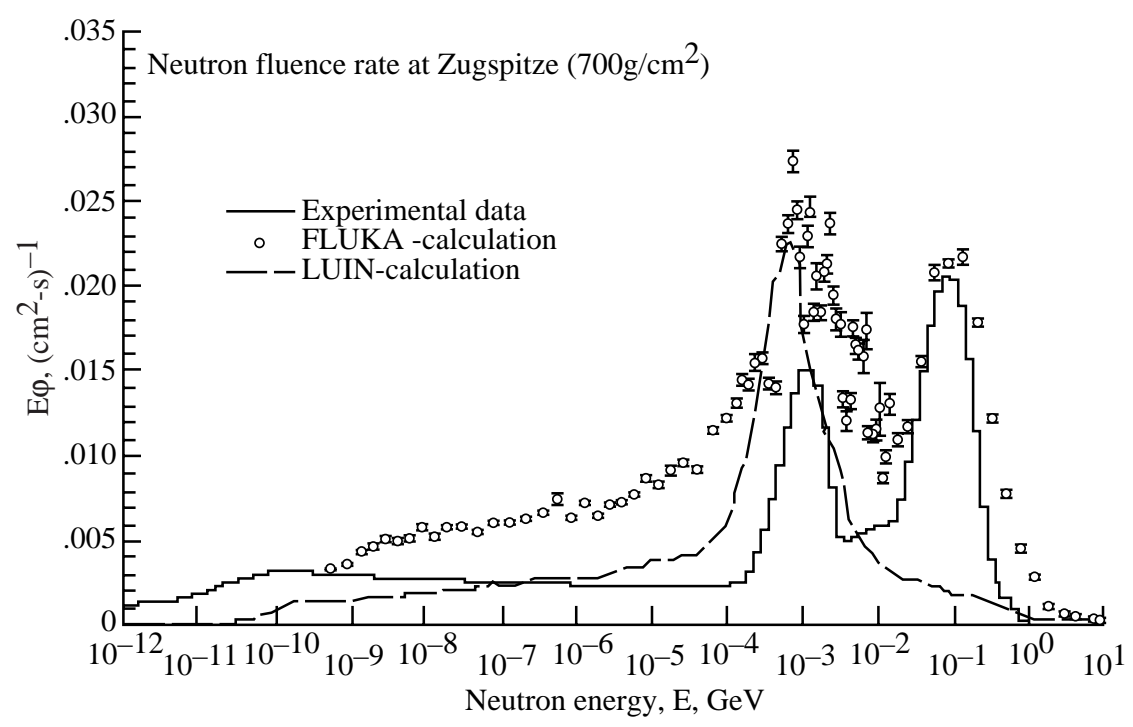

Figure 18. Spectral neutron fluence rate obtained by measurements and calculations on top of Zugspitze (by permission of Schraube et al. 1998).

environment, (b) the instruments had to be off-the-shelf operational equipment (c) each instrument must have an independent principal investigator to conduct data analysis, and (d) the instrument array must be able to measure all significant radiation components for which the NCRP (1996) had established minimal requirements. Also, the flight package had to be operational and the first flight occur before or near the maximum in the galactic cosmic ray intensity (ca. spring/summer 1997) and continue through the next cosmic ray minimum. The first flight series in June 1997 met with considerable success and is further discussed in these proceedings by Paul Goldhagen and others.

\section{Hypersonic Air Transport Vehicles}

There is continuing interest in hypersonic aircraft as the National Aerospace Plane and a Hypersonic Transport as the waverider (Pegg et al. 1993) which will fly at higher altitudes, perhaps over 100,000 ft. The radiation environment will continue to change character as the altitude is increased. For example, the high charge and energy (HZE) ions which have greatly attenuated in reaching HSCT altitudes (1 hit per gram tissue per month, Allkofer and Heinrich 1974) increase in number as the altitude is increased as shown in figure 19 according to the measurements of 


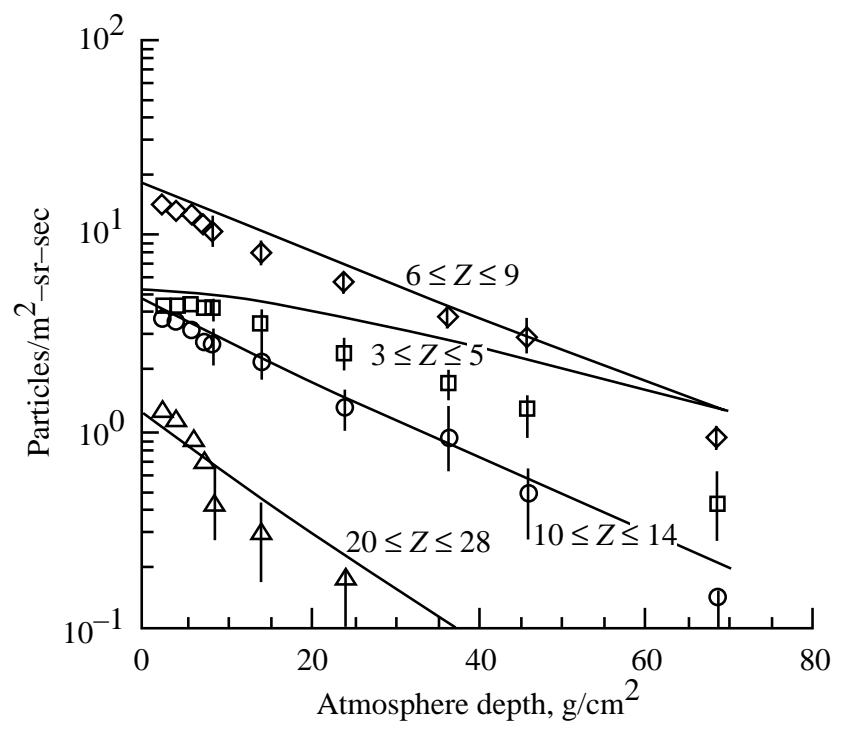

Figure 19. Vertical ion flux in upper atmosphere measured by Webber and Ormes (1967) and calculated by Wilson et al. (1987).

Webber and Ormes (1967) and calculations using the HZETRN code developed at the Langley Research Center (Wilson et al. 1987, 1991). Contributions to the dose equivalent during solar minimum in the polar region based on available data in 1995 is shown in table 5 . Clearly a major contribution comes from HZE ions as the altitude is increased which is an entirely new class of high LET radiations (compared to radiations at usual commercial operations) which have been of concern for high altitude flight for many years (Armstrong et al. 1950) since their discovery (Frier et al. 1948).

While it is true that the HZE ions have high LET, the secondary electrons which mediate the ion energy loss to biological action (Butts and Katz 1967) have significant energy resulting from the speed of the ion and carry the energy deposit far from the ion path (figure 20, see Cucinotta et al. 1995a). The ions in figure 20 are all of about $400 \mathrm{MeV} /$ nucleon resulting in an energy deposit which is laterally spread from the ion path by distances which are large compared to a cell nucleus as seen in the figure (Schaefer 1952). Health risk estimates for these particles are problematic because insufficient data exist to determine the RBE's with which to extrapolate the gamma ray exposure data (NCRP 1989, Schimmerling 1992). Furthermore, such ions may produce effects and associated biological end points for which gamma ray exposures are 
Table 5. Background Biological Exposure Components at High-Speed Altitudes in Polar Regions During Solar Minimum (1977)

\begin{tabular}{|c|c|c|c|c|}
\hline Component & $60000 \mathrm{ft}$ & $70000 \mathrm{ft}$ & $80000 \mathrm{ft}$ & $100000 \mathrm{ft}$ \\
\hline $\begin{array}{l}\dot{D}, \mu \mathrm{Gy}-\mathrm{hr}^{-1} \ldots \ldots \ldots \ldots \ldots \ldots \ldots \ldots \ldots \ldots \ldots \ldots \ldots \ldots \\
\left(\bar{Q}_{i}-1\right) \dot{D}_{i}:\end{array}$ & $5.9-7.8$ & $6.9-9.1$ & $7.4-9.7$ & $7.4-9.8$ \\
\hline Subnuclear, $\mu \mathrm{Sv}-\mathrm{hr}^{-1} \ldots \ldots \ldots \ldots$ & $\approx 0.01$ & $\approx 0.01$ & $\approx 0.01$ & \\
\hline Neutrons, $\mu \mathrm{Sv}-\mathrm{hr}^{-1} \ldots \ldots \ldots \ldots \ldots \ldots$ & $4.5-18.0$ & $5.0-20.0$ & $5.1-20.2$ & $2.1-8.4$ \\
\hline$Z=1, \mu \mathrm{Sv}-\mathrm{hr}^{-1} \ldots \ldots \ldots \ldots \ldots \ldots \ldots$ & $\approx 1.5$ & $\approx 1.8$ & $\approx 2.0$ & $\approx 2.5$ \\
\hline$Z=2, \mu \mathrm{Sv}-\mathrm{hr}^{-1} \ldots \ldots$. & $\approx 2.4$ & $\approx 2.6$ & $\approx 2.8$ & $\approx 3.1$ \\
\hline$Z>2, \mu \mathrm{Sv}-\mathrm{hr}^{-1} \ldots \ldots \ldots \ldots \ldots \ldots \ldots \ldots \ldots \ldots \ldots \ldots$ & $0.2-0.6$ & $0.6-1.7$ & $1.3-3.8$ & $9.6-12.7$ \\
\hline 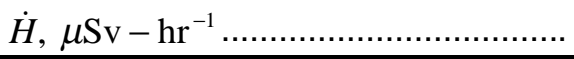 & $14.5-30.3$ & $16.9-35.2$ & $18.6-38.5$ & $24.7-36.5$ \\
\hline
\end{tabular}




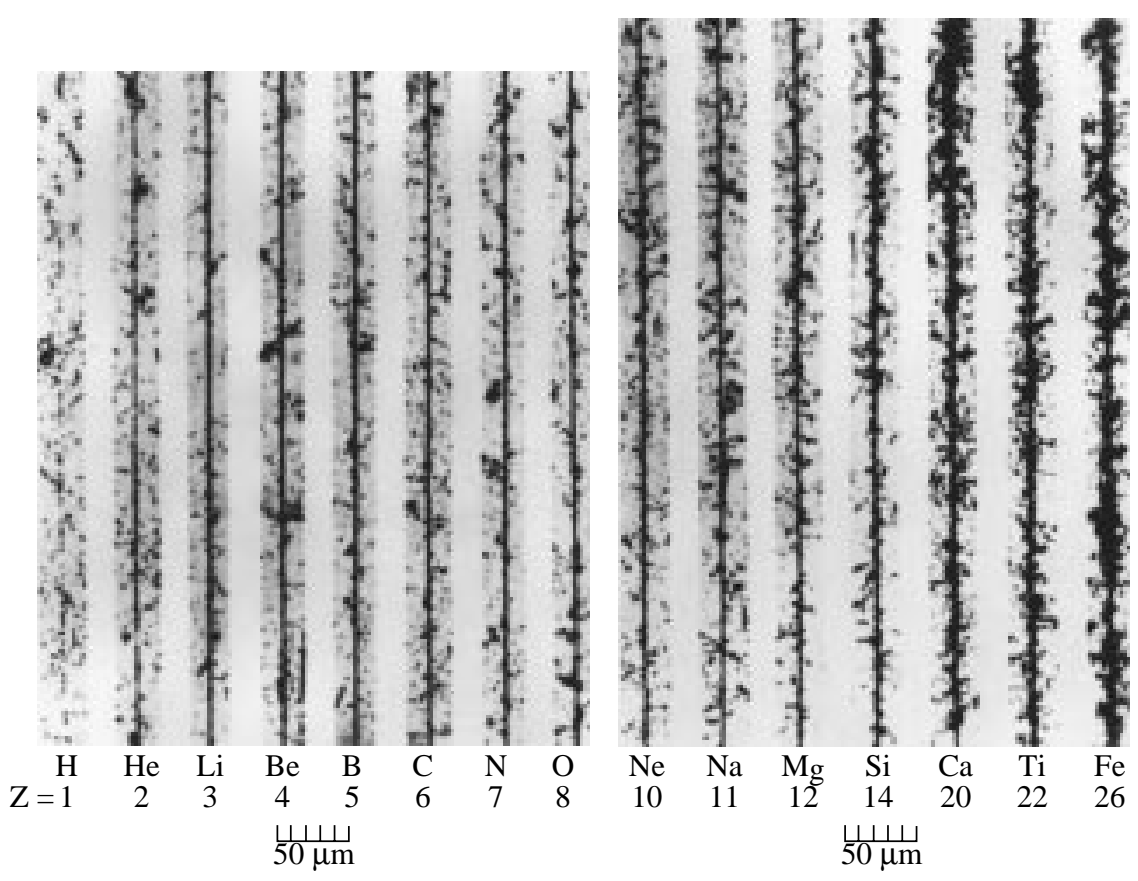

Figure 20. Cosmic-ray ion tracks in nuclear emulsion. (McDonald 1964).

incapable (that is, RBE is effectively infinite). Such RBE values are found in cellular exposures in the measurement of sister chromatid exchanges in resting human lymphocytes irradiated with Pu-238 alpha particles (Aghamohammadi et al. 1988), by the abnormalities in stem cell colonies surviving similar alpha particle irradiations (Kadhim et al. 1992), and by the partial disintegration of chromosomes after irradiation with multiply-charged ion beams (Kraft 1987). Todd has postulated that biological effects may occur at the tissue level by a single heavy ion traversal for which there is no corresponding gamma ray effect (Todd 1983). The establishment of exposure limits for such aircraft must await a gain in knowledge of the risks of such radiations. This is similar to our situation in deep space exploration as we shall see in the remainder of this paper.

\section{Space Exposure Limits}

The Earth's protective atmosphere is a massive $1 \mathrm{~kg} / \mathrm{cm}^{2}$ or equivalent mass of ten meters of water. There is little wonder that the cosmic ray levels are low on the surface and still modest at aircraft altitudes where only 25 percent of the atmosphere remains to protect subsonic aircraft 
and only 5 percent remains to shield the HSCT. Even so, 5 percent is equivalent to $50 \mathrm{~cm}$ of water. Even if one is above the atmosphere, there is still the geomagnetic field which provides protection from extraterrestrial radiations near the equator (low inclination orbits) but also poses a new hazard from those particles trapped in the geomagnetic field itself (see figure 2). In addition to the greater intensities of the space radiation environment, the astronaut is committed to 24 hours of exposure time for each work day unlike any other occupational exposure. For these reasons, astronaut exposure limits have always been considered outside the realm of other radiation related occupations.

A 1960 workshop on space exposures at the Langley Research Center concluded that the brief flights of the Mercury program at a $100 \mathrm{n}$. mi. low inclination orbit had no concern from radiation exposure (Jacobs 1960). However, a vigorous NASA space program would have much higher expected future exposures and would require a corresponding space radiation protection program. J. E. Pickering, of the Air Force School of Aviation Medicine, Wright Field, Ohio, suggested radiation risk should be in line with other mission risks: this then became a dominant theme in NASA's exposure-limits assessments. A clear balance was established between radiation risk and other mission risks for the high-risk exploratory Apollo mission (Billingham et al. 1965) with the operational exposure limits in table 6 . The intent was to assure survival of the astronauts in the event of a large solar particle event. Indeed the largest event so far observed occurred on Aug. 4, 1972, between Apollo 16 and 17. As space operations became more routine and of longer duration, a new set of exposure limits were appropriate as given by the National Academy of Sciences (1970) in table 7. Current recommendations by the NCRP (1989) adopted for shuttle operations and Space Station Freedom in low inclination Earth orbit are in table 8. As a result of the larger fatal cancer risk coefficient (BEIR 1980, ICRP 1991) the NCRP is reevaluating their recommendations. The higher allowable annual exposure limits for astronauts are defined to limit the lifetime excess fatal cancer risk to 3 percent for the brief late-in-life career of the astronaut (NCRP 1989). Note the current astronaut exposure limits allowed are comparable to the lifetime risks assumed by other radiation workers with maximal allowed exposures over a thirty five year career which begins at a relatively early age. 
Table 6. Exposure Limitations for Apollo Missions [Missions were approximatel y 2 weeks]

\begin{tabular}{lc}
\hline \multicolumn{1}{c}{ Organ } & $\begin{array}{c}\text { Exposure } \\
\text { limitations, } \\
\text { Sv }\end{array}$ \\
\hline Blood forming organ & 2.0 \\
Skin & 7.0 \\
Lens & 2.0 \\
Hands and feet & 9.8 \\
\hline
\end{tabular}

Table 7. Abbreviated Recommended Organ Dose Equivalent Limits [NAS 1970]

\begin{tabular}{cccc}
\hline \multirow{2}{*}{$\begin{array}{c}\text { Exposure } \\
\text { interval }\end{array}$} & \multicolumn{3}{c}{ Dose equivalent, Sv, for- } \\
\cline { 2 - 4 } & Blood forming organ & Skin & $\begin{array}{c}\text { Ocular } \\
\text { lens }\end{array}$ \\
\hline Career & 4.00 & 12.00 & 2.00 \\
Annual & 0.75 & 2.25 & 0.38 \\
30 Days & 0.25 & 0.75 & 0.13 \\
\hline
\end{tabular}

Table 8. Recommended Organ Dose Equivalent Limits [From NCRP 98]

\begin{tabular}{cccc}
\hline \multirow{2}{*}{$\begin{array}{c}\text { Exposure } \\
\text { interval }\end{array}$} & \multicolumn{3}{c}{ Dose equivalent, Sv, for- } \\
\cline { 2 - 4 } & Blood forming organ & Skin & Ocular lens \\
\hline Career & $\mathrm{a}_{1-4}$ & 6 & 4 \\
Annual & 0.5 & 3 & 2 \\
30 Days & 0.25 & 1.5 & 1 \\
\hline
\end{tabular}

aVaries with age and gender at initial exposure. 


\section{Low Earth Orbit Exposures}

The astronaut exposures at low inclinations are dominated by trapped radiation exposures and the maximum number of days within a $2 \mathrm{~g} / \mathrm{cm}^{2}$ shield per year of operation before reaching the exposure limit in table 8 is shown in figure 21. Clearly missions are time limited above a few hundred nautical miles depending on the amount of shielding. The environment is a function of solar activity and the measured dose on Shuttle is shown in comparison with calculated daily dose in low inclined orbits (Atwell et al. 1989) in figure 22. The two curves correspond to solar minimum and solar maximum where as actual flight data is randomly distributed over the solar cycle. The low altitude limit is dominated by the galactic cosmic rays. The quality factor will depend on the relative contribution of trapped protons and galactic cosmic rays which vary with altitude. The corresponding quality factors have been calculated based on measured LET distributions to be approximately 2.3 to 3.4 (Badhwar et al. 1997). It is clear from figure 22 that the main contributions are from the trapped radiations and extraterrestrial radiations play a minor role since the geomagnetic cutoffs are high. The low inclination orbital measurements for early Shuttle flights are shown in table 9 . The whole body dose equivalent is seen to have only slightly more low-LET components than high-LET components.

At higher orbital inclinations, the extraterrestrial radiations are more important due to the lower geomagnetic cutoffs at the highest latitudes. This allows the GCR to access these orbits and approximately half of the exposures are from the GCR (Badhwar et al. 1995, Wu et al. 1996) as

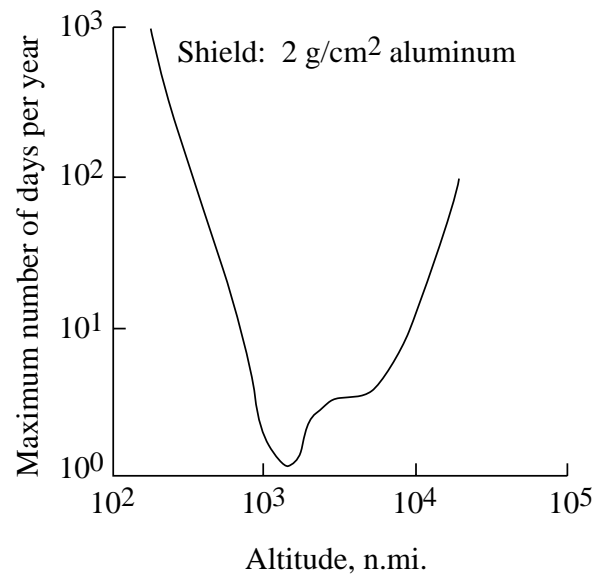

Figure 21. Limits imposed by trapped radiations on space operations with a $2 \mathrm{~g} / \mathrm{cm}^{2}$ aluminum shield. (Wilson et al. 1991) 


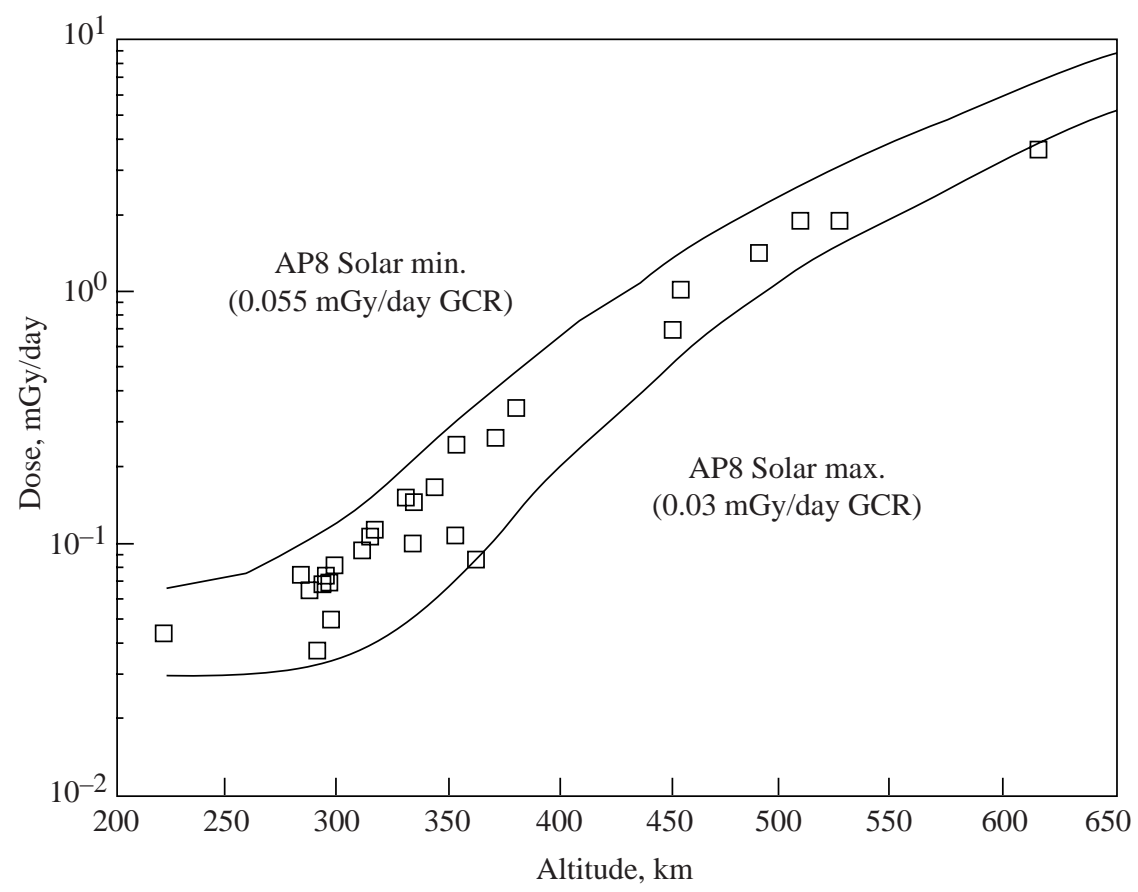

Figure 22. Shuttle measurements in low inclination LEO compared to model calculations (Atwell et al. 1989).

shown in table 10. Thus, the high LET components dominate the exposures in these orbits since a large fraction of the trapped radiations also result in high LET events (see table 9). Furthermore, the health risks from exposures to HZE ions of the GCR are unknown (NAS 1996).

In addition to the greater access of the GCR to highly inclined orbits, the solar particle events also have access to these orbits especially if a geomagnetic disturbance is in progress (Wilson et al. 1991, Nealy et al. 1996). Such a coincidence of a large geomagnetic storm and arrival of solar particles occurred during the Nov. 12-13, 1960 solar particle event. (A lesser storm also occurred during the Aug. 4, 1972 solar event.) We have modeled the time structure of the Oct. 1989 events in which a shock event was also modeled. The rise and decay of the proton flux was taken as 10 and 15 hours respectively. If a shock occurs it was assumed to rise and decay with 3 hour time constants and contain 70 percent of the total event. The geomagnetic storm was modeled after the Nov. 1960 storm event and the time at the peak of the proton flux was taken as a variable (see figure 23). The hourly averaged storm field 
Table 9. Shuttle Passi ve Dosi metry, in Low Incl ination Orbits Whole Body Dose Equivalent mSv

\begin{tabular}{cccccc}
\hline Mission & Duration (days) & Low-LET & Neutron & High-LET & Total \\
\hline STS-4 & 7.04 & 0.446 & 0.156 & 0.077 & 0.679 \\
STS-5 & 5.0 & 0.278 & 0.117 & 0.145 & 0.540 \\
STS-6 & 5.0 & 0.273 & 0.084 & 0.138 & 0.495 \\
STS-7 & 5.96 & 0.348 & 0.014 & 0.117 & 0.479 \\
STS-8 & 6.04 & 0.348 & 0.026 & 0.192 & 0.566 \\
<STS> & 5.81 & 0.339 & 0.079 & 0.134 & 0.552 \\
\hline
\end{tabular}

Table 10. Dosimetry Measurements and Calculations of Exposure for High Inclination Orbits (mSv/day)

\begin{tabular}{ccll}
\hline Mission & Trapped & GCR & Total \\
\hline Mir & 0.538 & 0.445 & 1.003 \\
ISS $^{\text {a }}$ & 0.33 & 0.28 & 0.61 \\
\hline
\end{tabular}

aSkin dose equivalent with $10 \mathrm{~g} / \mathrm{cm}^{2} \mathrm{Al}$ shield. 


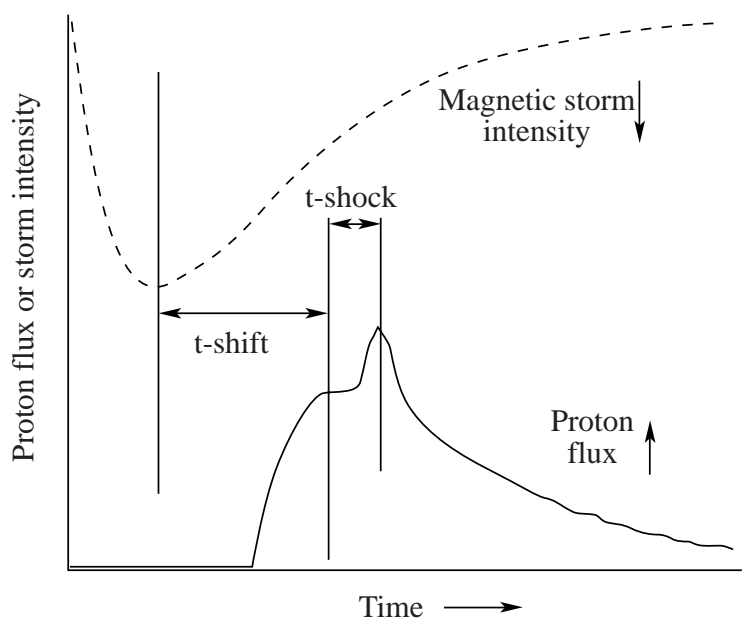

Figure 23. Schematic diagram of time variation and temporal relationships of solar proton flux and geomagnetic storm intensities.

increased to a peak value of -425 nanotesla over a ten hour period and decayed over the next 15 hours. Because the geomagnetic dipole moment is displaced with respect to the Earth's rotational axis and is tilted with north magnetic pole over Canada, the radiation per orbit depends on the line of nodes (Wilson et al. 1991). The calculated dose on the Shuttle at dosimeter location 1 is shown in figure 24 for coincidence of the peak of the storm and peak flux. The exposure is seen to be a strong function of the location of the ascending node with maximum exposure at 210 degrees. This orbit represents the nearest approach to the north magnetic pole at the time of peak flux and peak storm. The worst accumulated exposures as a function of the time between peak flux and peak disturbance is shown in figure 25. Clearly only a small fraction of the potential exposure from this event is able to penetrate to low Earth orbit even during a coincident geomagnetic storm. Early crew rotations may be required but no immediate effects of the exposure are expected.

\section{Deep Space Mission Exposures}

Outside the geomagnetosphere, astronauts are subject to the full galactic and solar cosmic ray environments except for what protection is afforded by the vehicle or spacesuit. The GCR are of low intensity and were not of concern in the Apollo mission which were of short duration (less than two weeks). The main concern was the possibility of a solar 


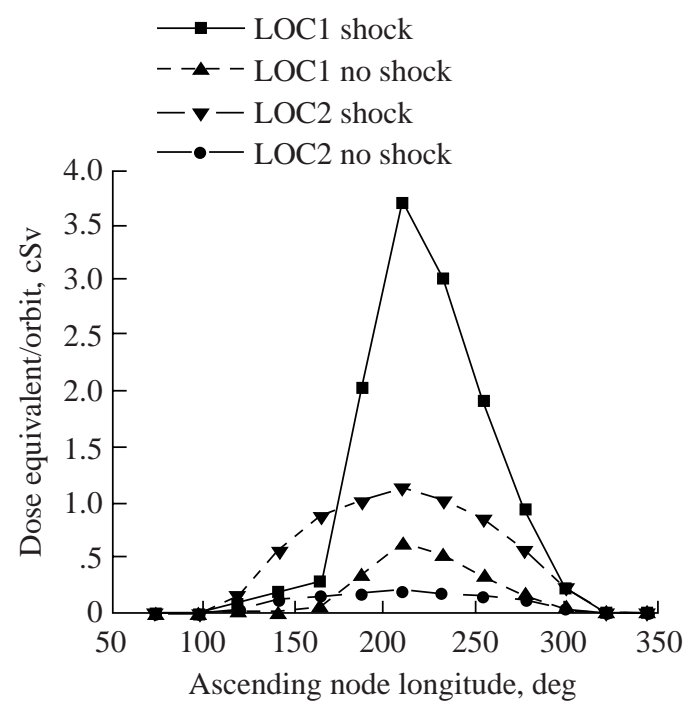

Figure. 24. Orbit-averaged dose equivalent as a function of ascending node longitude for coincident storm and solar proton flux peak intensities, with and without superimposed shock acceleration event.

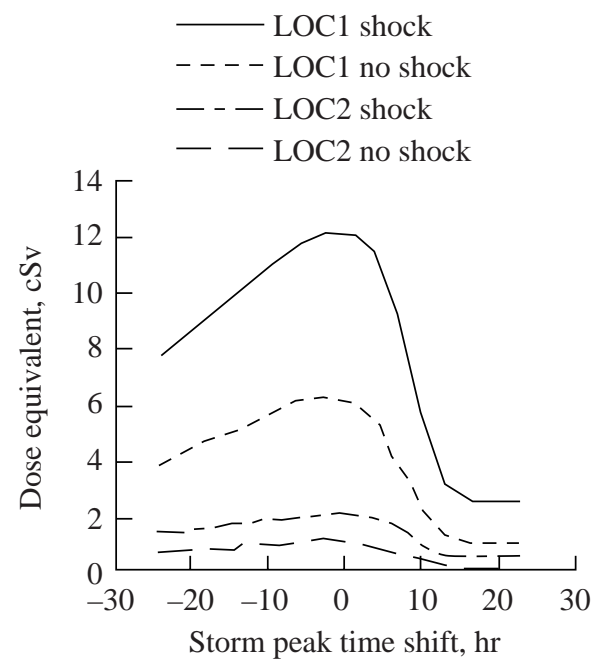

Figure 25. Total dose equivalent for 13 orbits centered on 210-degree ascending node longitude as a function of magnetic storm intensity and solar proton flux peak time difference. 
particle event in which acute effects may occur as was reflected in the design exposure limits in table 6 . As future space exploration is towards Mars and there is the possibility of a lunar colony, the long term exposures to galactic cosmic rays are a critical issue (NCRP 1989). There are no exposure standards for such missions established since the biological cancer risks and other adverse effects of exposures to the HZE ions are largely unknown (NAS 1996).

Galactic background exposures. The galactic cosmic rays are more intense outside the solar system and must overcome the outward convection of the solar wind. As the solar wind changes intensity over the changing solar cycle (see sunspot numbers in figure 11) there is a corresponding inverse variation in cosmic ray intensity within the solar system. The solar modulation zone extends to 100 astronomical units but intensities vary only slightly between Earth and Mars (about 10 percent or less, Fujii and McDonald 1997). We have used the galactic cosmic ray model of Badhwar and O'Niell (1992) interpolated by a modulation parameter driven by the Deep River neutron monitor data and projected to future dates using a statistical model on solar activity cycle to evaluate the annual cosmic ray exposures behind aluminum shielding for missions between Earth and Mars for the years 1955 to 2015 (see figure 26). Except for the two years at or near the minimum galactic cosmic ray intensity, it will be difficult to design shields to meet the exposure limits in table 8 recommended for low Earth orbital operations (also see Badhwar, et al. 1994). Although we do not know what health risks this carries for the astronaut (Schimmerling 1992), we can at least judge that these are serious exposures.

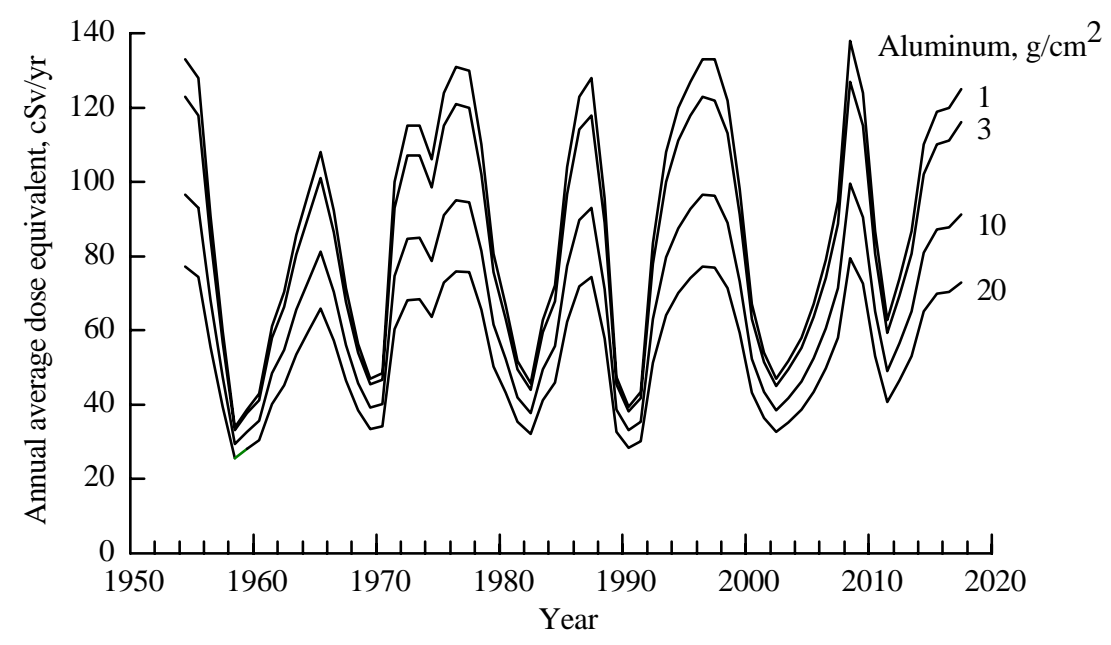

Figure 26. Annual exposure behind aluminum shielding in deep space. 
Although astronaut risk to HZE exposure is an unsolved problem, we can gain insight to future shield design by examining the implications of available biological data and biological models on shield effectiveness in reducing risks. Cucinotta has been in the forefront in the study of these issues (Cucinotta et al. 1991a, 1991b, 1992). There are several biological systems which have been extensively characterized in HZE exposures for which biological response models have been derived: mouse embryo cells (C3H10T1/2) for the endpoints of cell death and transformation (Yang et al. 1985, 1989, Wilson et al. 1993), Chinese hamster (V79) for cell death and HPRT mutations (Thacker et al. 1979, Kranert et al. 1990, Belli et al. 1993, and Kiefer et al. 1994, Cucinotta et al. 1995b), and harderian gland tumors in mice (Alpen et al. 1993, 1994, Cucinotta and Wilson 1994). Figure 27 shows the effects of penetrating GCR ions and their secondary radiations in arriving within a typical equipment room during solar minimum in deep space. Dose equivalent would imply contributions to fatal cancer according to conventional dosimetry but the relative effectiveness of various ion groups are more similar to that observed for cell death in C3H10T1/2 mouse cells. This is a coincidence and does not result from any fundamental principle. One would expect dose equivalent as a predictor of fatal cancer risks to be more nearly related to the risk of harderian gland tumors. Clearly, the dose equivalent as the underlying quantity for risk prediction is poorly correlated to the harderian gland tumor model (Wilson et al. 1997a). It is gratifying to see that the rate of mouse cell transformation is more indicative of the risks of harderian gland tumors. Although these types of studies are helpful in understanding the importance of knowledge of specific environmental components, the relationship to astronaut risk is unclear.

The biological risks depend on the local environment of the astronaut within the vehicle and the sensitivity of specific tissues to those radiations present. For example, the contributions to skin dose equivalent is shown in figure 28 for various charge groups as a function of energy. The calculations were done for solar minimum within a 5 $\mathrm{g} / \mathrm{cm}^{2}$ aluminum shield which is typical shielding for an equipment room on a space vehicle. The high energy peaks are due to the penetrating primary ions with modifications from secondary particles produced by the shield and the astronaut's body. The low energy peaks for charge 1 and 2 ions in figure 28 are locally produced reaction products in tissue and shield nuclei. The high energy peaks for all charge groups are from the penetrating primary ions with added contributions from secondary ions produced in the shield. Although neutrons play an important role in carrying the energy deeper into the shield and body tissues they do not 

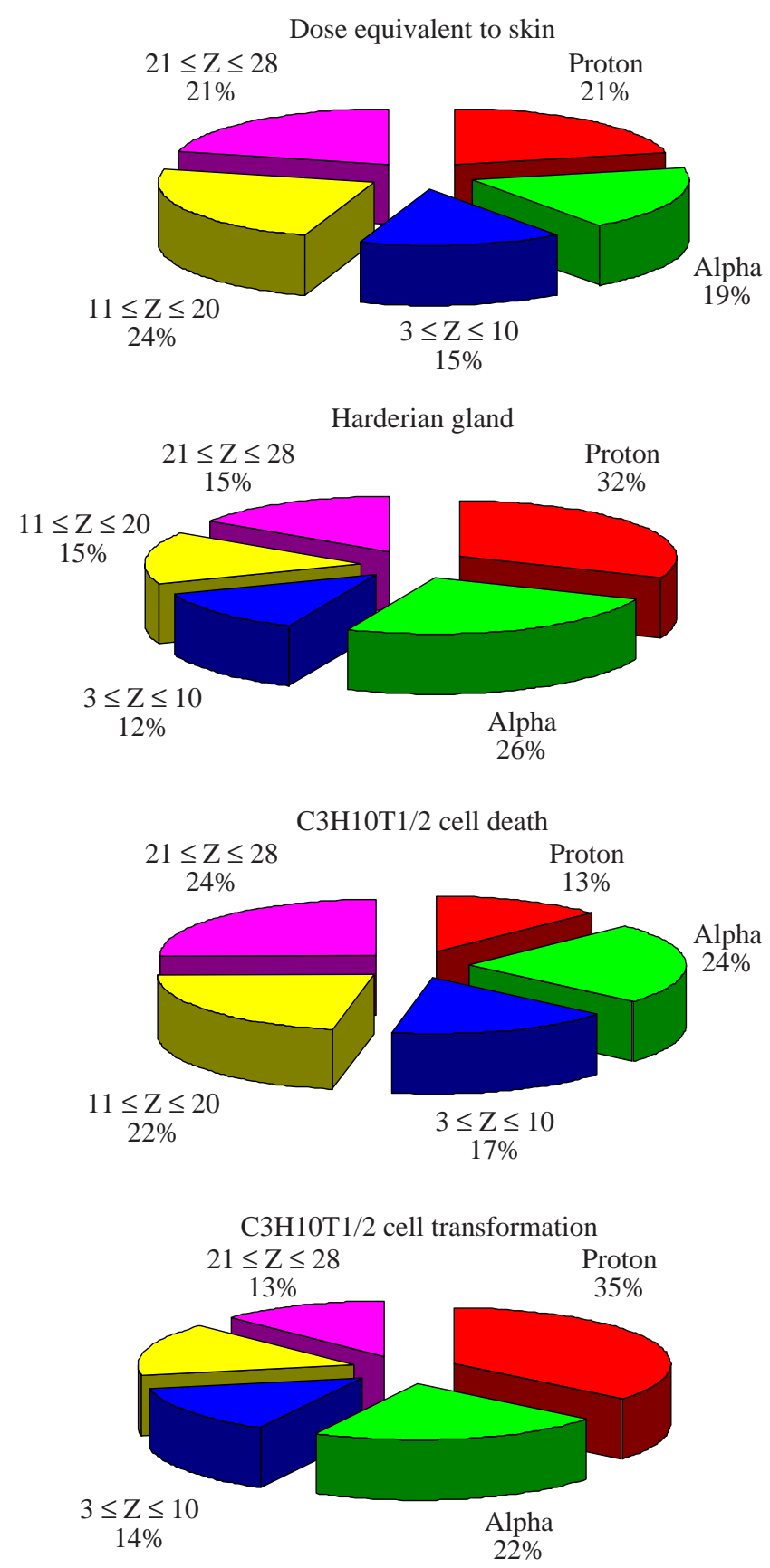

Figure 27. Estimated biological response contributions within an equipment room from penetrating GCR ions and secondary radiation. 


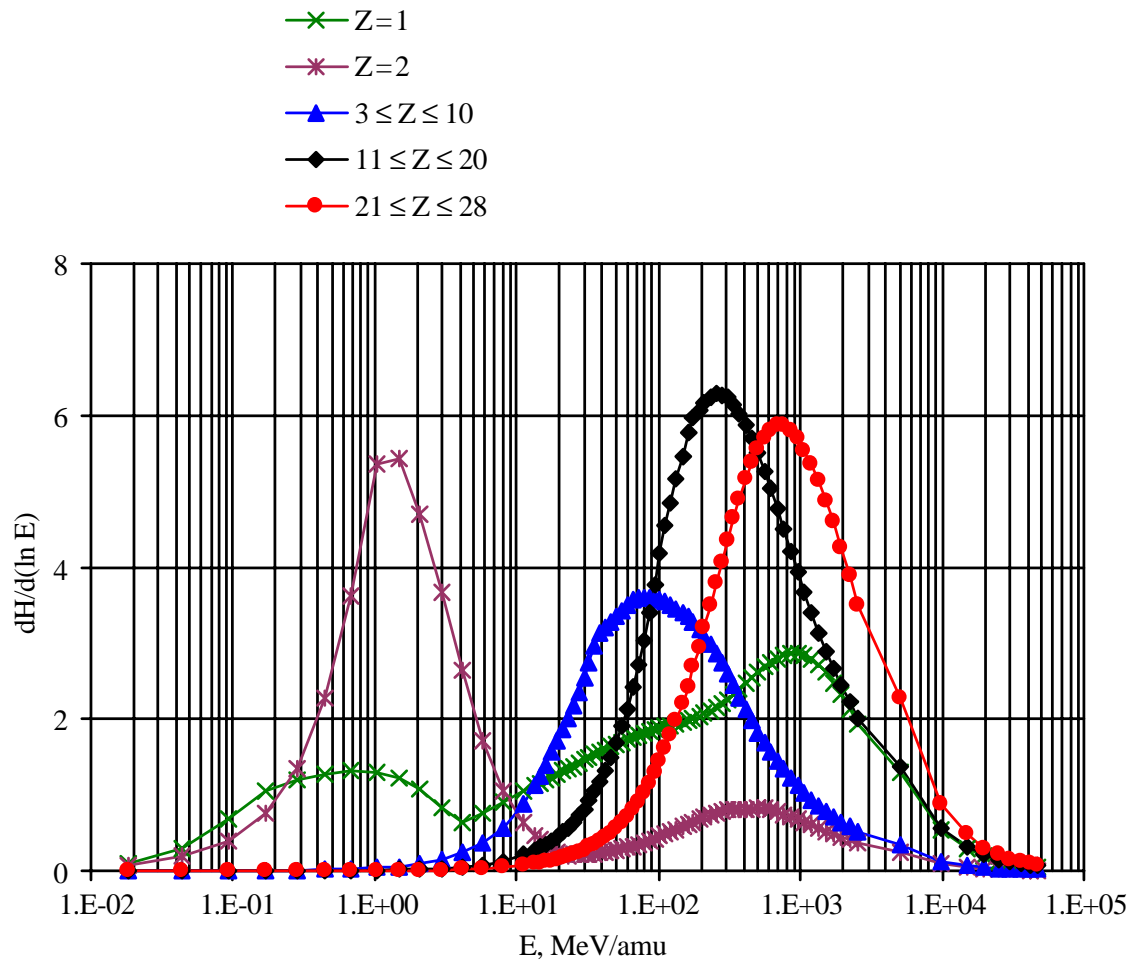

Figure 28. Annual skin dose equivalent contributions behind $5 \mathrm{~g} / \mathrm{cm}^{2}$ of aluminum at solar minimum.

appear explicity in the figure but have their effects in determining secondary charged particle components. Especially, the low energy charge 1 and 2 components. The relative contributions of these peaks is in part determined by the use of dose equivalent and other risk models would show different emphasis (Schimmerling et al. 1998) as can be seen from figure 27 . The value of figure 28 is the indication of critical experiments required to determine the HZE risks from galactic cosmic ray exposures. Significant contributions to risk are expected from HZE ions from a few hundred $\mathrm{MeV} /$ nucleon to several $\mathrm{GeV} /$ nucleon and experimental studies with such ions are needed before commitment to deep space exploration is made. The low energy peaks also emphasize the need to understand the collisional de-excitation process in high energy collisions and the corresponding biological effectiveness of these low energy light ions (Belli et al. 1993, Cucinotta et al. 1991b).

The details of the risk model also determine the value of specific materials as a protective shield (Wilson et al. 1995a). We use two 
examples, conventional dose equivalent and cell transformation in C3H10T1/2 cultures. The attenuation of these two quantities in several potential shield materials is shown in figure 29. Many materials are able to reduce dose equivalent by increasing shield mass. However, cell transformation in most materials is attenuated mainly by hydrogen bearing materials. Aluminum which is a standard shield material may increase the risks or at least provide no added protection over most shield thickness common to the earlier space program. Polymeric
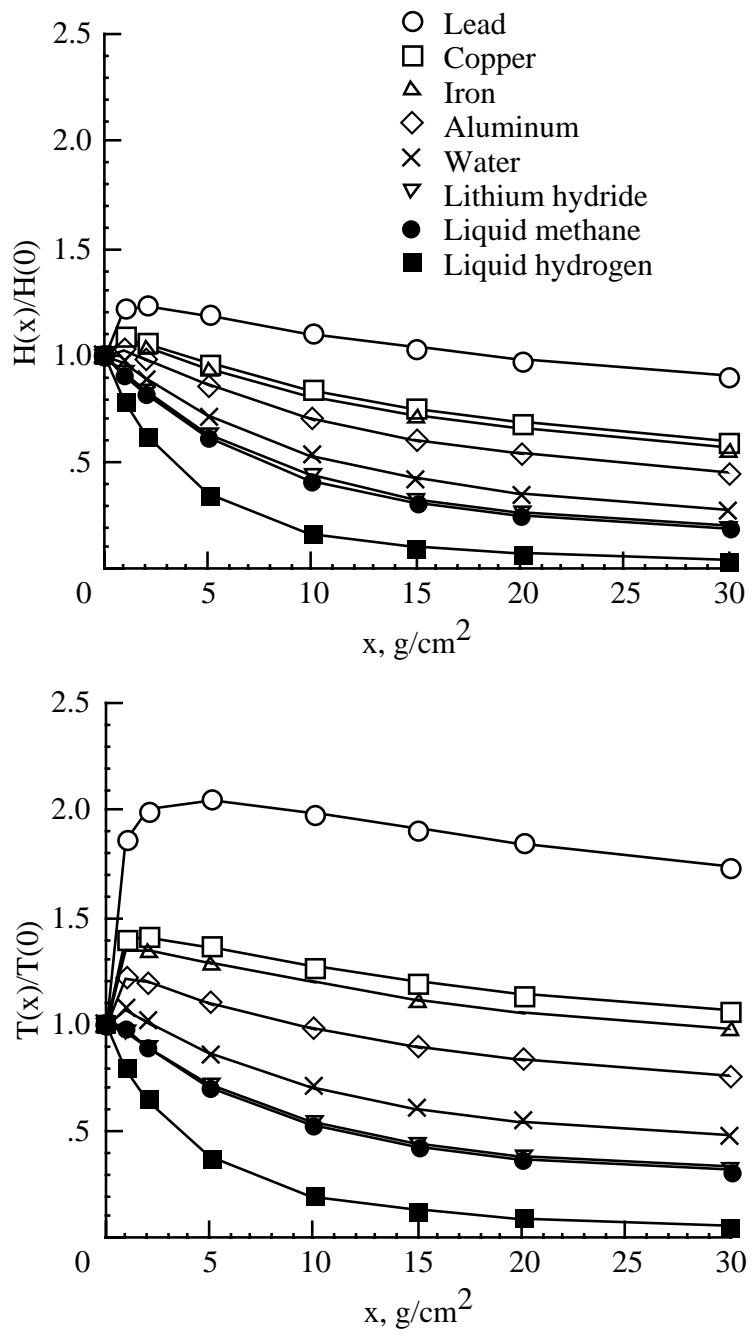

Figure 29. Attenuation of dose equivalent and cell transformation in one year exposure at solar minimum behind several shield materials. 
materials which are receiving more use in spacecraft construction appear to be a good material for both models. Clearly the final shield design for GCR background in a Mars or lunar mission will require an improved understanding of the risks to HZE ions (Wilson et al. 1995a, NAS 1996). These results also bring to question the health risk within the International Space Station and its primarily aluminum structure designed using dose equivalent estimates and the LEO limitations on exposure for the low inclination orbit of Space Station Freedom (NCRP 1989).

Solar particle event exposures. Only twice have astronauts been in deep space during a solar particle event (Apollo 14 and 16, Nealy et al. 1992) although an extraordinary event occurred on August 4, 1972, between Apollo 16 and 17. Estimated exposures for this event are quite high if inadequate preparation is made (Wilson and Denn 1976). A recent evaluation (Wilson et al. 1997b) is in table 11 and should be compared to the threshold of biological response in table 12 estimated by the NCRP (1989) and Langham (1967). This event had the clear potential for disturbing biological effects especially in relation to other space stress factors to which the astronaut is subjected (Schimmerling 1992, Wilson et al 1997b, Schimmerling et al. 1998). As important as the Aug. 1972 event was, there is an approximate 3 percent probability that an even larger event may occur (Feynman et al. 1990). Such a mission would have monitoring devices to help the astronaut to make decisions to asure adequate protection, still there is the chance of a large unplanned exposure.

An important issue in solar particle event exposures is that these exposures occur over a several hour period and repair and recovery of the affected tissues are simultaneously in progress. The threshold erythema dose is known to increase by a factor of over 2 when the dose is delivered over a several hour period (Langham 1967). To estimate the importance of such factors we have used response models developed by the military for tactical nuclear warfare (Jones 1981) and found that the

Table 11. August 4, 1972 Solar Particle Event Exposures (Sv) behind Aluminum Shielding in deep space. (event duration $\approx 10$ hours)

\begin{tabular}{cccc}
\hline Organ & Spacesuit & Equip Room & Shelter \\
\hline Skin & 93.6 & 4.3 & 1.1 \\
Lens & 38.3 & 3.7 & 1.0 \\
BFO & 2.8 & 0.7 & 0.24 \\
\hline
\end{tabular}


Table 12. Exposure Levels for Single, High-Dose Rate Exposure at Which Health Effects Appear in Healthy Adults [F rom NCRP 1989 and Laugham 1967]

\begin{tabular}{|c|c|}
\hline Health effect & $\begin{array}{l}\text { Dose, } \mathrm{X} \text { or gamma } \\
\text { radiation, Gy }\end{array}$ \\
\hline 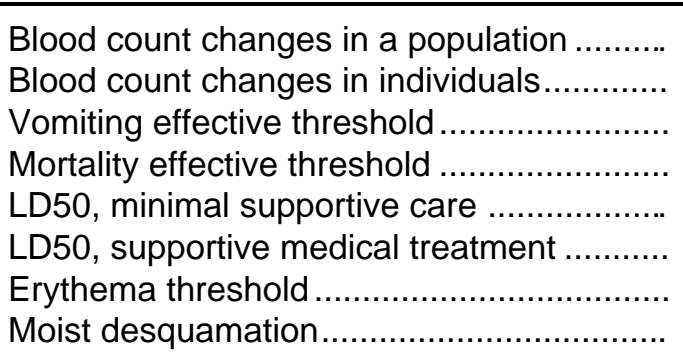 & $\begin{array}{r}0.15-0.25 \\
0.5 \\
1.0 \\
1.5 \\
3.2-3.6 \\
4.8-5.4 \\
6.0 \\
30.0\end{array}$ \\
\hline
\end{tabular}

dose rate effectiveness factor for BFO response to the August 1972 event is about a factor of three (Wilson et al. 1997b). This gives a comfortable margin for potential lethal effects from this exposure. Even with dose rate effectiveness factors on the order of a factor of 2 or 3 , space suit exposures are near or above threshold of severe skin reaction, possible vomiting, and observable changes in the bloood levels. These effects would be eliminated by modest increase in protection. How applicable are these models to an astronaut in space is a question since it is well known that a number of important physiological changes take place in space which may alter the biological response to such exposures. Clearly attention needs to be given to address the modification of biological response due to space stress related factors.

Recently there has been attention drawn to the HZE ions in solar particle events especially in those with "iron rich" spectra. We have used the September 29, 1989 event as one such example. This event is the largest ground level event observed since Feb. 23, 1956. The Deep River neutron monitor count rate is shown in figure 30 and should be compared to figures 12 and 13 . We have used the spectral data for $O$ and Fe ions compiled by Tylka et al. (1997) and the scaled baseline distribution of McGuire et al. (1986) to estimate the full particle event spectra. The HZETRN code (Wilson et al. 1995a) was used to evaluate the exposures of the astronaut organs in three simplified shield configurations. The contributions to critical organ dose equivalents are given in table 13. Although significant contributions from various HZE ions are seen for the skin exposures in a spacesuit, they are small compared to the contributions from charge 1 and 2 components which 


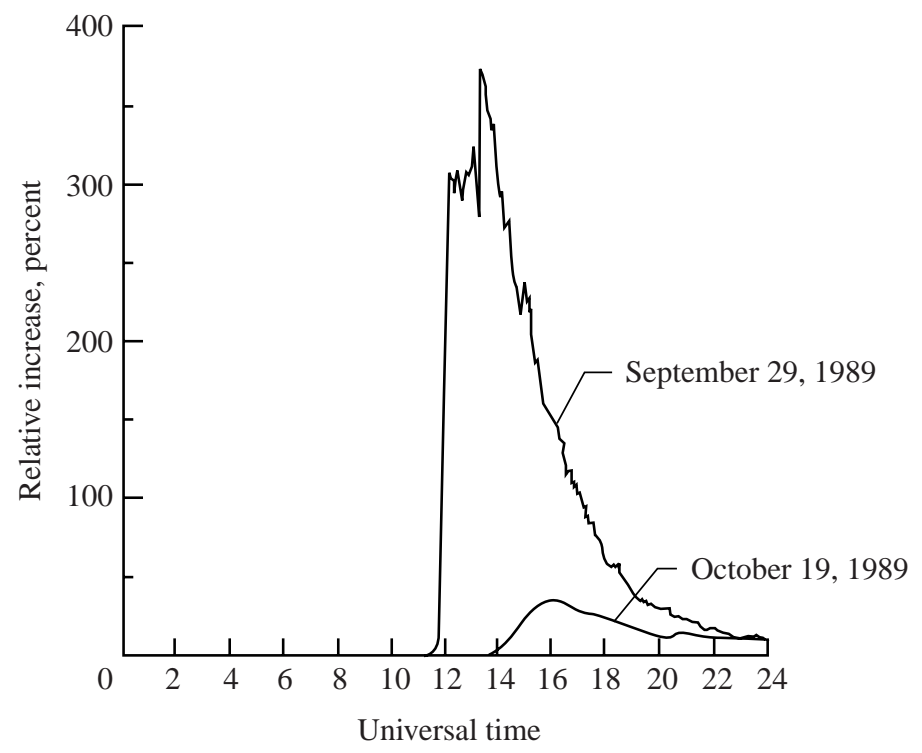

Figure 30. Deep River neutron monitor count rates during the solar particle events of October 19 and September 29 of 1989.

are dominated by penetrating protons and alpha particles. The HZE are quickly attenuated by additional shielding or in reaching deeper organs.

\section{Concluding Remarks}

The exposures of the average US citizen from natural radiations in order of importance are inhaled radon $(2 \mathrm{mSv})$, other primordial radioactive nuclei ingested or as terrestrial gamma rays $(0.63 \mathrm{mSv})$, and galactic cosmic rays $(0.27 \mathrm{mSv})$. A significant fraction of the total natural exposure $(3.4 \mathrm{mSv})$ is of high LET components (radon and ingested radioactive nuclei) for which the biological risk factors are most uncertain. The only other significant exposure $(0.4 \mathrm{mSv})$ is the medical exposures given for the persons benefit and health. All other sources are insignificant.

Average terrestrial occupational exposures $(2.2 \mathrm{mSv})$ are on the order of the background exposures of the average US citizen (3.4 mSv) and are dominated by low LET components (93 percent). The terrestrial occupational exposure risk coefficient is among the best known of all exposed groups as estimated in table 14 . 
Table 13. Dose equivalent to critical organs within space shiel ding configurations from several charge groups of the Sept. 29, 1989 Solar Particle event

\begin{tabular}{crrrrc}
\hline & \multicolumn{5}{c}{ Dose Equivalent (cSv) form- } \\
\cline { 2 - 6 } & $\mathrm{z}=1$ & $\mathrm{z}=2$ & $3 \leq \mathrm{z} \leq 10$ & $11 \leq \mathrm{z} \leq 20$ & $21 \leq \mathrm{z} \leq 28$ \\
\hline Spacesuit: & & & & & \\
Skin & 1738.3 & 1149 & 53.2 & 9.0 & 2.4 \\
Lens & 668.1 & 132.3 & 9.3 & 2.4 & 1.0 \\
BFO & 37.8 & 4.0 & 0.1 & 0.1 & 0.1 \\
Press Vessel & & & & & \\
Skin & 553.7 & 81.6 & 5.3 & 1.6 & 0.8 \\
Lens & 317.8 & 33.1 & 2.4 & 0.9 & 0.5 \\
BFO & 31.4 & 3.5 & 0.1 & 0.1 & 0.1 \\
Eq. Room & & & & & \\
Skin & 57.7 & 6.6 & 0.2 & 0.1 & 0.2 \\
Lens & 50.1 & 4.9 & 0.2 & 0.1 & 0.1 \\
BFO & 16.8 & 2.4 & - & - & - \\
\hline
\end{tabular}


Table 14. Annual exposure, quality of exposure, and risk coefficient uncertainty of US radiation workers

\begin{tabular}{lcccc}
\hline \multicolumn{1}{c}{ Group } & $\begin{array}{c}\text { Exposure } \\
\text { mSv }\end{array}$ & $\begin{array}{c}\text { Quality } \\
\text { Low LET, \% }\end{array}$ & $\begin{array}{c}\text { Distribution } \\
\text { High LET, \% }\end{array}$ & $\begin{array}{c}\text { Risk } \\
\text { uncertanty } \\
\text { factor }\end{array}$ \\
\hline $\begin{array}{l}\text { Terrestrial } \\
\text { occupatons }\end{array}$ & 2.2 & 93 & 7 & $2.1-3.8$ \\
Aircraft: & & & & \\
$\quad$ Subsonic & $5-9$ & 32 & 68 & $3.4-10.8$ \\
supersonic & $8-17$ & 32 & 68 & $3.4-10.8$ \\
hypersonic & $14-21$ & 28 & $72^{*}$ & $3.4-11.6$ \\
LEO: & 17 & 62 & 38 & $2.8-7.6$ \\
low incl. & 144 & 34 & $66^{*}$ & $3.3-10.9$ \\
high incl. & 500 & 14 & $86^{* *}$ & $3.7-13.3$ \\
Deep space & 50 & & & \\
\hline${ }^{*}$ Significant exposures to HZE ions. & & & \\
${ }^{* *}$ Expsoure dominated by HZE ions. & &
\end{tabular}


Aircraft background exposures are mainly from galactic cosmic rays and their secondaries produced in collision with air nuclei and aircraft materials. These exposures are characterized by a significant fraction of high LET components leading to greater uncertainty in the corresponding cancer risk coefficient as shown in table 14 . This uncertainty is important since aircrew working on high latitude routes (62 percent of international flights) are among the most exposed group of radiation workers (5 to 9 mSv for 700 block hours on subsonic aircraft). Of particular note are exposures of pregnant crew members for which prenatal exposure risks are poorly known. The exposure rates are even higher by up to a factor of two on supersonic flight and the current uncertainty in the environment will not allow meaningful exposure management (NCRP 1996). Significant levels of HZE exposures are experienced in hypersonic flight for which risks from background exposures are problematic. Since cancer risk and prenatal risk from HZE ions are unknown.

Exposures in low Earth orbit with low inclination have a large contribution from low LET components for which the risk coefficient is relatively well defined. The reverse is true for high inclination where a significant fraction of the exposure is from HZE ions (table 14). Even the shield design based on dose equivalent as in the case of the International Space Station may be misleading with respect to control of the health risk.

Deep space mission exposures from background are dominated by HZE ions and the corresponding risk uncertainties are large (NAS 1996). Traditional construction materials like aluminum probably increase the health risks but polymeric materials show some usefulness in shielding the astronaut from the HZE ions.

Very rare solar particle events may produce exposures at subsonic aircraft altitudes greater than newly recommended exposure limits but acceptable to present standards in force (see table 1). The exposures at supersonic altitudes are an order of magnitude higher and caution is noted even with today's exposure standards. Special procedures will be required for passengers and especially pregnant occupants of such aircraft. Most disturbing in this respect are recent experiments on developmental injury of mouse embyro in which use of quality factors for fatal cancer may seriously underestimate the associated prenatal risks. Clearly, further studies of developmental injury with radiation sources more characteristic of atmospheric radiations are needed.

Solar particle event exposures in LEO are limited by the natural precessional motion of the spacecraft even in the event of a concurrent 
large geomagnetic storm. Crew rotation may be required after such an event but health risks are managable. In deep space, solar events can present a serious health hazard and adequate monitoring with a warning system and storm shelter design is required. Large exposures are possible if adequate shelter is not acquired in a timely fashion. Still lethality is not likely since tissue repair greatly reduces the effect of exposure and especially if adequate medical planning is part of the mission design. Space stress could greatly alter the biological response to such exposures and an adequate understanding of space stress affects is necessary to mission planning.

\section{References}

AGHAMOHAMMADI, S. Z., GOODHEAD, D. T., AND SAVAGE, J. R. (1988). "Induction of sister chromatid exchanges (SCE) in G0 lymphocytes by plutonium-238 alpha-particles." Int. J. Radiat. Biol. \& Relat. Stud. Phys., Chem., and Med. 53, 909-915.

ALLKOFER, O. C., HEINRICH, W. (1974). "Measurement of galactic cosmic ray nuclei at supersonic transport altitudes and their dosimetric significance." Health Phys. 27, 543-551.

ALPEN, E. L., POWERS-RISIUS, P., CURTIS, S. B., AND DEGUZMAN, R. (1993). "Tumorgenic potential of high LET, charged particle radiations." Radiat. Res. 136, 282-391.

ALPEN, E. L., POWERS-RISIUS, P., CURTIS, S. B., DEGUSMAN, R., AND FRY, R.J.M. (1994). "Fluence based relative biological effectiveness for charged particle carcinogenesis in mouse harderian glanc." Adv. Space Res. 14, 573-582.

ANON. (1975). "Cosmic radiation exposure in supersonic and subsonic flight." Aviat., Space, \& Environ. Med. 46, 1170-1185.

ANON. (1993). "Report on a workshop to examine methods to arrive at risk estimates for radiation-induced cancer in the human based on laboratory data." Radiat. Res. 135, 434-437.

ARMSTRONG, H., HABER, H., STRUNGHOLD, H. (1949), "Aero medical problems of space travel-panel meeting, School of Aviation Medicine," J. Aviation Med. 20, 383-417.

ARMSTRONG, T. W.; Chandler, K. C., AND BARISH, J. (1973) "Calculation of neutron flux spectra induced in Earth's atmosphere by galactic cosmic rays." J. Geophys. Res. 78, 2715. 
ARMSTRONG, T. W., ALSMILLER, R. G., AND BARISH, J. (1969). "Calculation of the radiation hazard at supersonic aircraft altitudes produced by an energetic solar flare. Nucl. Sci. Eng 37, 337-342.

ATWELL, W., BEEVER, E.R., HARDY, A. C., RICHMOND, R. G., AND $\mathrm{CASH}, \mathrm{R}$. L. (1989). "Space radiation shielding analysis and dosimetry for the space Shuttle program." High-Energy Radiation Background in Space," A. C. Rester, and J. I. Trombka, eds., AIP Conference Proceedings 186, New York, 289-296.

BADHWAR, G. D. AND O'NIELL, P. M. (1992). "Improved model of galactic cosmic radiation for space exploration missions." Nucl. Tracks \& Radiat. Meas. 20, 403-410.

BADHWAR, G. D., CUCINOTTA, F. A., AND O'NEILL, P. M. (1994). "An analysis of interplanetary space radiation exposure for various solar cycles." Radiat. Res. 138, 201-208.

BADHWAR, G. D., KONRADI, A., ATWELL, W., GOLIGHTLY, M. J., CUCINOTTA, F. A., WILSON, J. W., PETROV, V. M., TCHERNYKH, I. V., SHURSHAKOV, V. A., AND LOBAKOV, A. P. (1995). "Measurments of the linear energy transfer spectra on the Mir orbital station and comparison with radiation transport models." Radiat. Meas. 26, 147-158.

BADHWAR, G. D., ET AL. (1997). "Intercomparison of radiation measurements on STS-63." Radiat. Meas. 26, 901-916.

BARISH, R. J. (1990). "Health physics concerns in commercial aviation." Health Phys. 59, 199-204.

BEIR, (1980). Health effects of exposure to low levels of ionizing radiation: BEIR V. Natl. Acad. Press.

BETHE, H. A., KORFF, S. A., AND PLACZEK, G. (1940). "On the interpretation of neutron measurements in cosmic radiation," Phys. Rev. 57, 573-587.

BELLI, M., CERA, F., CHERUBINI, R., HAQUE, A. M., IANZINI, F., MOSCHINI, G., SAPORA, O. SIMONE, G. TABOCCHINI, M. A., AND TIVERTON, P. (1993). "Inactivation and mutation induction in V79 cells by low energy protons: re-evaluation of the results at the LNL facility." Intern. J. Radiat. Biol. 63, 331-337.

BILLEN, D. (1990). "Spontaneous DNA damage and its significance for the 'negligible dose' controversy in radiation protection," Radiat. Res. 124, 242-245.

BILLINGHAM, J., ROBBINS, D. E., MODISETTE, J. L., AND HIGGINS, P. W. (1965). "Status report on the space radiation effects on the Apollo 
mission." Second Symposium on Protection Against Radiations in Space, Arthur Reetz, ed., NASA SP-71, 139-156.

BOEING CO. (1969). Computation of galactic cosmic radiation exposure during aircraft flights. Seattle, WA: Document No. DGA 11471-1.

BRAMLITT, E. T. (1985) "Commercial Aviation Crewmember radiation doses." Health Phys. 49, 945-948.

BUTTS, J. J. AND KATZ, R. (1967). "Theory of RBE for heavy ion bombardment of dry enzymes and viruses." Radiat. Res. 30, 855-871.

CUCINOTTA, F. A., KATZ, R., WILSON, J. W., TOWNSEND, L. W., NEALY, J. E., AND SHINN, J. L. (1991a). Cellular Track Model of Biological Damage to Mammalian Cell Cultures from Galactic Cosmic Rays. NASA TP-3055.

CUCINOTTA, F. A., KATZ, R., WILSON, J. W., TOWNSEND, L. W., NEALY, J. E., AND SHINN, J. L. (1991b). "Biological effectiveness of high-energy protons: Target fragmentation." Radiat. Res. 127, 130-137.

CUCINOTTA, F. A., WILSON, J. W., TOWNSEND, L. W., SHINN, J. L., AND KATZ, R. (1992). "Track structure model for damage to mammalian cell cultures during solar proton events." Nucl. Tracks and Radiat. Meas. 20, 177-184.

CUCINOTTA, F. A. AND WILSON, J. W. (1994). "An initiation promotion model of tumor prevalence from high charge and energy radaitions." Phys. Med. Biol. 39, 1811-1831.

CUCINOTTA, F. A., KATZ, R., WILSON, J. W., AND DUBEY, R. R. (1995a). "Distributions in the delta-ray theory of track structures." Proceedings of Two-Center Effects in Ion-Atom Collisions" AIP Conference Proceedings, 1995.

CUCINOTTA, F. A., WILSON, J. W., SHAVERS, M. R., AND KATZ, R. (1995b). "Effects of track structure and cell inactivation on the calculation of heavy ion mutation rates in mammalian cells." Intern. J. Radiat. Biol. 69, 593-600.

CURTIS, S. B., NEALY, J. E., WILSON, J. W. (1995). "Risk cross sections and their application to risk estimation in the galactic cosmic-ray environment," Radiat. Res. 141, 57-65.

FEYNMAN, J., ARMSTRONG, T. P., DAO-GIBNER, L. AND SILVERMAN, S. (1990). "New interplanetary proton fluence model." J. Spacecr. 27, 403-410.

FOELSCHE, T. (1961). Radiation Exposure in Supersonic Transports. NASA TN D-1383. 
FOELSCHE, T., AND GRAUL, E. H. (1962). "Radiation Exposure in Supersonic Transports," Atompraxis, 8, 365-380.

FOELSCHE, T., MENDELL, R. B., WILSON, J. W., ADAMS, R. R. (1974). Measured and calculated neutron spectra and dose equivalent rates at high altitudes: relevance to SST operations and space research, NASA TN D-7715.

FRIEDBERG, W., NEAS, B. R. (1980). Cosmic ray exposures during air travel. FAA-AM-80-2, FAA, Washington, D.C.

FRIEDBERG, W., FAULKNER, D. N., SNYDER, L., DARDEN, E. B., O'BRIEN, K. (1989). "Galactic cosmic radiation exposure and associated health risks for air carrier crewmembers." Aviat., Space, and Environ. Med. 60, 1104-1108.

FRIER, P., LOFGREN, E. J., NEY, E. P., AND OPPENHEIMER, F. (1948). "The heavy component of the primary cosmic rays." Phys. Rev. 74, 1818-1827.

FUJII, Z., AND MCDONALD, F. B. (1997). "Radial intensity gradients of galactic cosmic rays." J. Geophys. Res.102 (A11), 24,201-24,208.

HAJNAL, F., AND WILSON, J. W. (1991). "High-altitude cosmic-ray neutrons: a significant contributor to the radiation exposures at aircraft altitudes." Seventh Symposium on Neutron Dosimetry, Berlin, October 14-18, 1991.

HAJNAL, F., AND WILSON, J. W. (1992) "High-altitude cosmic ray neutrons: probable source for the high energy protons at the earth's radiation belts." In proc. 8th Congress Intl. Radiat. Prot. Ass. Montreal, p 1620, 1992.

HARDER, D. (1995). Wilhelm Conrad Roentgen- the dignity of discovery. In Radiation Research 1985-1995 Congress Proceedings, Vol. 2, pp 11-21, Universitatsdreckerei H. Sturtz AG, Wurzburg.

HALLIDAY, D. (1962). Introductory Nuclear Physics, Wiley and sons, New York, 1962.

HESS, V. F., AND EUGSTER, J. (1949). Cosmic Radiation and Its Biological Effects, Fordham University Press, New York.

HESS, W. N., CANFIELD, E. H., AND LINGENFELTER, R. E. (1961). "Cosmic-ray neutron demography." J. Geophys. Res. 66, 665-667.

HEWITT, J. E., HUGHES, L., BAUM, J. W., KUEHNER, A. V., MCCASLIN, J. B., RINDI, A., SMITH, A.R. STEPHENS, L. D., THOMAS, R. H., GRIFFITH, R. V., AND WELleS, C. G. (1978). "Ames 
collaborative study of cosmic ray neutrons mid-latitude flights." Health Phys. 34, 375-384.

ICAO (1995). "Annex 6: To the converntion on International Civil Aviation, Part I: International Commercial Air Transport-Aeroplanes" International Standards and Recommended Practices. Sixth Edition of Part I, July 1995. International Civil Aviation Organization.

ICRP Task Group (1966). "Radiobiological aspects of the supersonic transport." Health Phys. 12, 209-226.

ICRP (1977). Recommendations of the international commission on radiological protection. ICRP Publ. 26, Oxford, Pergamon Press.

ICRP (1991). The 1990 Recommendations of the International Commission for Radiological Protection, ICRP Report 60, Pergamon Press, Oxford, UK.

ICRU (1986). The quality factor in radiation protection. ICRU Rep. 40, Bethesda, M.D.

JACOBS, G. J., ed. (1960). Proceedings of Conference on Radiation Problems in Manned Space Flight. NASA TN D-588.

JIANG, T.-N., LORD, B. I., HENDRY, J. H. (1994). "Alpha particles are extremely damaging to developing hemopoiesis compared to gamma irradiation." Radiat. Res. 137, 380-384.

JONES, T. D. (1981). "Hematologic syndrome in man modeled from mammalian lethality." Health Phys. 41, 83-103.

KADHIM, M. A., MACDONALD, D. A., GOODHEAD, D. T., LORIMORE, S. A., MARSDEN, S. J., AND WRIGHT, E. G. (1992) "Transmission of chromosomal instability after plutonium a-particle irradiation." Nature 355, 738-740.

KIEFER, J., STOLL, U. AND SCHNEIDER, E. (1994). "Mutation induction by heavy ions." Adv. Space Res. 14(10), 257-265.

KRANERT, T., SCHNEIDER, E. AND KIEFER, J. (1990). "Mutation induction in V79 Chinese hamster cells by very heavy ions." International J. of Radiat. Bilo. 58, 979-987.

KRAFT, G. (1987). "Radiobiological effects of very heavy ions: Inactivation, induction chromosome aberrations, and strand breaks." Nucl. Sci. Appl. A, 3, 1-28.

LAMBIOTTE, J. J., WILSON, J. W., AND FILIPPAS, T. A. (1971). PROPER-3C: A Nucleon-Pion Transport Code. NASA TM X-2158. 
LANGHAM, W. H. (1967). Radiobiological Factors in Manned Space Flight. National Academy of Science Publ. 1487.

LEBUSER, H. J. (1993). "Round table discussion." Radiat. Prot. Dosim. 48, 136-138.

MCAULAY, I. R., BARTLETT, D. T., DIETZE, G., MENZEL, H. G., SCHNUER, K., AND SCHREWE, U. J. (1996). Exposure of air crew to cosmic radiation. European Radiation Dosimetry Group, EURADOS report 1996-01.

MCDONALD, F. B., (1964). "Review of Galactic and Solar Cosmic Rays." Second Symposium on Protection Against Radiations in Space, Arthur Reetz , ed., NASA SP-71, 19-29.

MCGUIRE, R. E., VON ROSENVINGE, T. T., AND MCDONALD, F. B. (1986). "The composition of solar energetic particles." The Astrophys. J. 301, 938-961.

MCMEEKIN, R. R. (1990). Radiation exposure of air carrier crewmembers. FAA Advis. Circ. No. 120-52, Mar. 1990.

MERKER, M. (1973). "Contributions of galactic cosmic rays to atmospheric neutron maximum dose equivalent as function of neutron energy and altitude." Health Phys. 25, 524.

NAS (1970). Radiation Protection Guides and Constraints for Space Mission and Vehicle Design Involving Nuclear Systems, National Academy Press, Washington, DC.

NAS (1996). Radiation Hazards to Crews of Interplanetary Missions: Biological Issues and Research Strategies. National Academy Press, Washington, DC.

NCRP (1987). Ionizing Radiation Exposure of the Population of the United States, NCRP Report 93, Bethesda, MD.

NCRP (1989). Guidance on Radiation Received in Space Activities. NCRP Report 98.

NCRP (1993). Limitation of exposure to ionizing radiation. NCRP Rep. 116, Bethesda, MD.

NCRP (1996). Radiation exposures and high-altitude flight. NCRP commentary No. 12, NCRP, Bethesda, MD.

NEALY, J. E., WILSON, J. W., SHEA, M. A., AND SMART, D. F. (1996). "Effects of orbit progression on the radiation exposures from solar proton fluxes in low Earth orbit under geomagnetic storm conditions." Adv. Space Res. 17(2), 117-120. 
NEALY, J. E., SIMONSEN, L. C., AND STRIEPE, S. A. (1992). "Natural radiation environment fluence and dose predictions for missions to the moon and Mars." New Horizons in Radiation Protection and Shielding, ANS Topical Meeting, April 26-May 1, 1992, Pasco WA, pp. 181-187.

NEHER, H. V. (1961). "Cosmic-ray knee in 1958." J. Geophysical Res. 66, 4007-4012.

NEHER, H. V. AND ANDERSON, H. R. (1962). "Cosmic rays at balloon altitudes and the solar cycle." J. Geophysical Res. 67, 1309-1315.

O'BRIEN, K. AND MCLAUGHIN, J. E. (1972). "Radiation dose to man from galactic cosmic rays." Health Phys. 22, 225-232.

O'BRIEN, K., AND FRIEDBERG, W. (1994). "Atmospheric cosmic rays at aircraft altitudes." Enviornment International 20, 645-663.

PARKER, J. F., AND WEST, V. R., eds. (1973). Bioastronautics Data Book, Second edition, NASA SP-3006.

PEGG, R. J., HUNT, J. L., PETLEY, D. H., BURKARDT, L., STEVENS, D. R., MOSES, P. L., PINCKNEY, S. Z., KABIS, H. Z., SPOTH, K. A., DZIEDZIC, W. M., KREIS, R. K., MARTIN, J. G., AND BARNHART, P. J. (1993). Design of a Hypersonic Waverider-derived Airplane, AIAA 93-0401, 31st Aerospace Sciences Meeting \&Exhibit, Reno, January 11-14.

REITZ, G., SCHNUER, K., SHAW, K. (1993). "Editorial--Workshop on radiation Exposure of civil aircrew." Radiat. Prot. Dosim. 48, 3.

ROESLER, S., HEINRICH, W., AND SCHRAUBE, H. (1998). "Calculation of Radiation Fields in the Atmosphere and Comparison to Experimental Data." Radiat. Res. 149, 87-97.

SCHAEFER, H. J. (1950). "Evaluation of present-day knowledge of cosmic radiation at extreme altitude in terms of the hazard to health," J. Aviation Med. 21, 375-94.

SCHAEFER, H. J., (1952). "Exposure hazards from cosmic radiation beyond the stratosphere and in free space." J. Aviation Med. 23, 334-344.

SCHAEFER, H. J. (1959). "Radiation and man in space." Adv. Space Res. 1, 267-339.

SCHRAUBE, H., LEUTHOLD, G., ROESLER, S., AND HEINRICH, W. (1998). Neutron spectra at Flight Altitudes and Their Radiological Estimation." Adv. in Space Res. in press.

SHEA, M. A., AND SMART, D. F. (1990). "A summary of major solar proton events." Solar Physics 127, 297-320. 
SCHIMMERLING, W. (1992). "Radiobiological problems in space--An overview." Radiat. \& Environ. Biophys. 31, 197-203.

SCHIMMERLING, W., WILSON, J. W., CUCINOTTA, F. A., AND KIM, M. Y. (1998). "Evaluation of risks from space radiations." Radiat. \& Environ. Biophys. to be published.

SHEA, M. A., AND SMART, D. F. (1993). "History of energetic solar protons for the past three solar cycles including cycle 22 update." Biological Effects and Physics of Solar and Galactic Cosmic Radiation, C. E. Swenberg, G. Horneck, G. Stassinopoulos, eds. Plenum Press, 37-71.

STOERMER, C. (1955). The Polar Aurora, Oxford at the Clarendon Press.

THACKER, J., STRETCH, A., AND STEPHENS, M. A. (1979). "Mutation and inactivation of cultured mammalian cells exposed to beams of accelerated heaby ions. II. Chinese hamster V79 cells." International J. of Radiat. Bilo. 36, 137-248.

TODD, P. (1983). "Unique biological aspects of radiation hazards--An overview." Adv. Space Res. 3,187-194.

TYLKA, A. J., DIETRICH, W. F., AND BOBERG, P. R. (1997). "Observations of very high energy solar heavy ions from IMP-8." Proceedings of the Twentyfifth International Cosmic Ray Converence 1, 101-104.

UPTON, A. C. (1989). Radiobiology and Radiation Protection: The Past Century and Prospects for the Future. NCRP Lecture No. 13, Bethesda.

UNITED NATIONS SCIENTIFIC COMM. ON EFFECTS OF ATOMIC RADIATION (1988). Sources, effects and risks of ionizing radiation1988 report to the General Assembly, United Nations.

VAN ALLEN, J. A., LUDWIG, G. H., RAY, E. C., MCILLWAIN, C. E. (1958). "Observation of high intensity radiation by satellites 1958 Alpha and Gamma," Jet Propulsion, 28, 588-592.

VON FRIEBEN, A. (1903). "Hodenverauderungen bei tieren nach Rontgenstrahlung," Muchen Med. Wuhnschi 50, 2295.

WALLACE, R.G. AND SONDHAUS, C. A. (1978). "Cosmic ray exposure in subsonic air transport." Aviation Space, \& Environ. Med. 74, 6494-6496.

WEBBER, W. R., AND ORMES, J. F. (1967). "Cerenkof-scintillation counter measurements of nuclei heavier than helium in the primary cosmic radiation. 1. Charge composition and energy spectra between 
$200 \mathrm{MeV} /$ nucleon and $5 \mathrm{beV/nucleon."} \mathrm{j.} \mathrm{Geophys.} \mathrm{Res.--Space} \mathrm{Phys.}$ 72, 5957-5976.

WEHR, M. R., RICHARDS, J. A. (1960). Physics of the Atom, AddisonWesley Publ., Reading, MA.

WILSON, J. W., LAMBIOTTE, J. J., FOELSCHE T. AND FILIPPAS, T. A. (1970). Dose Response Functions in the Atmosphere Due to Incident High-Energy Protons with Application to Solar Proton Events. NASA TN D-6010.

WILSON, J. W. AND DENN, F. M. (1976). Preliminary Analysis of the Implications of Natrural Radiations on Geostationary Operations. NASA TN D-8290.

WILSON, J. W., TOWNSEND, L. W., AND BADAVI, F. F. (1987). "Galactic HZE propagation through the Earth's atmosphere." Radiat. Res. 109, 173-183.

WILSON, J. W., TOWNSEND, L. W. (1988). "Radiation Safety in commercial air traffic: a need for further study." Health Phys. 55, 1001-1003; 56, 973-974.

WILSON, J. W., SHINN, J. L., AND TOWNSEND, L. W. (1990). "Nuclear reaction effects in conventional risk assessment for energetic ion exposures." Health Phys. 58, 749-752.

WILSON, J. W., TOWNSEND, L. W., SCHIMMERLING, W., KHANDELWAL, G. S., KHAN, F., NEALY, J. E., CUCINOTTA, F. A., SIMONSEN, L. C., SHINN, J. L., NORBURY, J. W. (1991) Transport methods and interactions for space radiation. NASA RP-1257.

WILSON, J. W., CUCINOTTA, F. A., AND SHINN, J. L. (1993). Cell kinetics and track structure. Biological Effects and Physics of Solar and Galactic Cosmic Radiation. C. E. Swenberg, G. Horneck, G. Stassinopoulos, eds. Plenum Press, 295-338.

WILSON, J. W., KIM, M., SCHIMMERLING, W., BADAVI, F. F., THIBEAULT, S. A., CUCINOTTA, F. A., SHINN, J. L., AND KEIFER, R. (1995a). "Issues in space radiation protection: Galactic cosmic rays." Health Phys. 68, 50-58.

WILSON, J. W., NEALY, J. E., CUCINOTTA, F. A., SHINN, J. L., HAJNAL, F., REGINATTO, M., AND GOLDHAGEN, P. (1995b). Radiation safety aspects of commercial high-speed flight transportation. NASA TP-3524.

WILSON, J. W., KONRADI, A., MILLER, J., AND CUCINOTTA, F. A. (eds.) (1997a) Shielding strategies for human space exploration. NASA CP-3360. 
WILSON, J. W., SHINN, J. L., SIMONSEN, L. C., CUCINOTTA, F. A., DUBEY, R. R., JORDAN, W. R., JONES, T. D., CHANG, C. K., AND KIM, M. Y. (1997b). Exposures to Solar Particle Events in Deep Space. NASA TP-3668.

WU, H., ATWELL, W., CUCINOTTA, F. A., AND YANG, C. H. (1996) Estimate of Space Radiation-Induced Cancer Risks for International Space Station Orbits. NASA TM-104818.

YANG, T. C., CRAISE, L. M., MEI, M. T., AND TOBIAS, C. A. (1985). "Neoplastic cell transformation by heavy charged particles." Radiat. Res. 104, S-177-S-187.

YANG, T. C., CRAISE, L. M., MEI, M. T., AND TOBIAS, C. A. (1989). "Neoplastic cell transformation by high-LET radiation: Molecular mechanisms." Adv. Space Res. 9(10), 131-147. 